\title{
Sprouting of Brainstem-Spinal Tracts in Response to Unilateral Motor Cortex Stroke in Mice
}

\author{
Lukas C. Bachmann, ${ }^{1,2 \star}$ Nicolas T. Lindau, ${ }^{1,2 *}$ Petra Felder, ${ }^{1,2}$ and Martin E. Schwab ${ }^{1,2}$ \\ ${ }^{1}$ Brain Research Institute, University of Zurich, 8057 Zurich, Switzerland, and ${ }^{2}$ Department Health Sciences and Technology, ETH Zürich, 8057 Zurich, \\ Switzerland
}

\begin{abstract}
After a stroke to the motor cortex, sprouting of spared contralateral corticospinal fibers into the affected hemicord is one mechanism thought to mediate functional recovery. Little is known, however, about the role of the phylogenetically old, functionally very important brainstem-spinal systems. Adult mice were subjected to a unilateral photothrombotic stroke of the right motor cortex ablating $90 \%$ of the cross-projecting corticospinal cells. Unilateral retrograde tracing from the left cervical spinal hemicord devoid of its corticospinal input revealed widespread plastic responses in different brainstem nuclei 4 weeks after stroke. Whereas some nuclei showed no change or a decrease of their spinal projections, several parts of the medullary reticular formation as well as the spinally projecting raphe nuclei increased their projections to the cortically denervated cervical hemicord by 1.2- to 1.6-fold. The terminal density of corticobulbar fibers from the intact, contralesional cortex, which itself formed a fivefold expanded connection to the ipsilateral spinal cord, increased up to 1.6-fold specifically in these plastic, caudal medullary nuclei. A second stroke, ablating the originally spared motor cortex, resulted in the reappearance of the deficits that had partially recovered after the initial right-sided stroke, suggesting dependence of recovered function on the spared cortical hemisphere and its direct corticospinal and indirect corticobulbospinal connections.
\end{abstract}

Key words: brainstem; plasticity; recovery; sprouting; stroke; tracing

\section{Introduction}

Cortical motor areas, giving rise to the direct corticospinal tract, are crucial for skilled movements (e.g., individual finger movements) (Heffner and Masterton, 1983). However, the corticospinal tract is only one of several parallel routes from the brain to the spinal cord. Decerebrated cats (Bignall and Schramm, 1974) and rodents (Woods, 1964; Berridge, 1989) show substantial motor abilities, including locomotion, clumsy object holding, and grooming. Stepwise-decorticated monkeys regained the ability to run around (Travis and Woolsey, 1956), and a newborn with a brain reduced to midbrain and hindbrain was reported to produce synergistic muscle contractions, enabling it to move the arm to the mouth (Gamper, 1926). Increasing evidence suggests an importance of brainstem reticular areas not only for proximal arm function but also wrist and digit movements (Riddle and Baker, 2010; Soteropoulos et al., 2012). In monkeys, bilateral

Received Oct. 14, 2013; revised Jan. 22, 2014; accepted Jan. 27, 2014.

Author contributions: L.C.B., N.T.L., and M.E.S. designed research; L.C.B., N.T.L., and P.F. performed research; L.C.B. and N.T.L. contributed unpublished reagents/analytic tools; L.C.B., N.T.L., and P.F. analyzed data; L.C.B., N.T.L., and M.E.S. wrote the paper.

This work was supported by the Swiss National Science Foundation Grant 31-138676/1, the National Center for Competence in Research "Neural Plasticity and Repair" of the Swiss National Science Foundation, the Spinal Cord Consortium of the Christopher and Dana Reeve Foundation, and the seventh Framework Program FP7/2007-2013 of the European Union by the European Stroke Network (201024 and 202213) and the HEALTH collaborative project PLASTICISE (223524)

The authors declare no competing financial interests.

*L.C.B. and N.T.L. contributed equally to this work.

Correspondence should be addressed to Dr. Lukas C. Bachmann, Department Health Sciences and Technology, ETH Zürich, Winterthurerstrasse 190, 8057 Zürich, Switzerland. E-mail: Iukas.bachmann@alumni.ethz.ch.

DOI:10.1523/JNEUROSCI.4384-13.2014

Copyright $\odot 2014$ the authors $\quad 0270-6474 / 14 / 343378-12 \$ 15.00 / 0$ pyramidotomy induces transient motor deficits that recover to a large extent (Lawrence and Kuypers, 1968a), which depends on brainstem-spinal tracts (Lawrence and Kuypers, 1968b).

The contributions of the brainstem as source of, or relay site for, supraspinal motor commands after stroke are incompletely understood (Rossini et al., 2003; Jankowska and Edgley, 2006; Baker, 2011). Upon stimulation of the remaining motor cortex in patients that recovered from a complete removal of one hemisphere or stroke, ipsilateral movements could be elicited (Benecke et al., 1991; Caramia et al., 1996). Although controversies exist (Hallett, 2001), this may have been mediated by direct corticospinal or corticoreticulospinal pathways (Benecke et al., 1991).

Restructuring of spinal projections is seen after stroke or spinal cord damage (Kartje-Tillotson et al., 1985; Rouiller et al., 1991; Raineteau and Schwab, 2001; Ghosh et al., 2009). In response to unilateral CNS damage, midline-crossing corticospinal fibers were observed: spinal cord injury (Ghosh et al., 2009; Rosenzweig et al., 2010), pyramidotomy (Brus-Ramer et al., 2007; Maier et al., 2008), and stroke (Omoto et al., 2011; Ueno et al., 2012; Liu et al., 2013). However, factors causing this growth and specificity of this response remain poorly understood, and a comprehensive study of sprouting of spinal-projection systems, other than the corticospinal tract, in response to stroke is missing.

Here, we studied the ability of 29 different spinally projecting cortical and subcortical brain areas to expand into the cervical hemicord, which has lost the majority of its cortical input after stroke. Recovery was accompanied by sprouting of corticospinal, reticulospinal, and corticoreticular fibers. Brainstem-spinal neurons with newly formed projections into the affected hemicord were six times more numerous than corticospinal neurons. This 
suggests a role of indirect corticoreticulospinal pathways for functional adaptation and recovery after stroke.

\section{Materials and Methods}

\section{Study design}

The primary aim of this study was to compare the ability of different spinally projecting regions in the brain to form new connections into the cervical hemicord, which has lost its main corticospinal input because of stroke. In adult mice, the connections of different regions into the cortically denervated hemicord were assessed by retrograde tracing and subsequent quantification of labeled cell bodies in 29 different areas of the brain. Intact animals were compared with animals that had recovered from stroke for 4 weeks. Surgeries were randomized, and experimenters were blinded where possible. Blinding was not possible for tissue reconstruction because of the obvious stroke-induced loss of cells and the prominent scar tissue. Automated quantifications of reconstructed brains and anterograde tracings were performed with equal parameters for all groups. All chronic animals with a stroke ablating the primary motor cortex and all animals with a tracer injection limited to one side of the spinal cord are included and shown. No statistical outliers were excluded.

\section{Animals and anesthesia}

For all experiments, adult female C57BL/6J mice were used. All experimental procedures were approved by the veterinary authorities (Zurich, Switzerland). For all surgeries, mice were anesthetized by a subcutaneous injection of Hypnorm (12.5 mg/kg, VetPharma) and Dormicum (12.5 mg/kg, Roche Pharma). Body temperature was maintained at $37^{\circ} \mathrm{C}$ on a heating pad.

\section{Photothrombotic stroke}

In 28 mice, a photothrombotic stroke was induced to unilaterally lesion the sensorimotor cortex as previously described (Lee et al., 2007). Briefly, mice were anesthetized and placed in a stereotactic frame (Kopf Instruments). The skull was exposed by a midline incision of the scalp. The entire skull was covered by an opaque template, which spared the region of the right motor cortex (i.e., rostral to caudal -2.5 to $2.5 \mathrm{~mm}$, medial to lateral 0 to $3 \mathrm{~mm}$ in relation to bregma) (Tennant et al., 2011). Five minutes after intraperitoneal injection of $0.1 \mathrm{ml}$ Rose Bengal $(13 \mathrm{mg} / \mathrm{kg}$ body weight, $10 \mathrm{mg} / \mathrm{ml}$ Rose Bengal in $0.9 \% \mathrm{NaCl}$ solution), the skull was illuminated by a cold light source (Olympus KL1500LCD, 150 W, $300 \mathrm{~K}$ ) attached to the stereotactic frame for $10 \mathrm{~min}$ at maximum output. Animals were allowed to recover on a heating pad for at least $24 \mathrm{~h}$.

After recovery from the first stroke (i.e., $28 \mathrm{~d}$ after lesion), a small group of animals $(n=4)$ received a second photothrombotic stroke of the left motor cortex (i.e., contralateral to the initial stroke) to test its contribution to functional recovery. The same protocol was used.

\section{Behavioral testing}

Behavioral testing was performed in 12 animals before (baseline) and 2, 4, 7 , 14,21 , and $28 \mathrm{~d}$ after photothrombotic stroke of the right motor cortex. Animals that received a second stroke of the left motor cortex were tested additionally on day 2, 4, and 7 after the second lesion. Apart from the accelerating rotarod test, all behavioral tasks were videotaped (Panasonic HDCSD800 High Definition Camcorder) and evaluated using frame-by-frame analysis (VideoReDo TV Suite, H.264, DRD Systems).

Accelerating rotarod. Animals were tested on the accelerating rotarod apparatus (model 7750, TSE Systems; gradual acceleration 4-20 revolutions per minute) for 5 minutes. For each animal and time point, the average latency to fall off the rod of four trials was recorded.

Vertical rope. The vertical rope setup consisted of an anchored rope (diameter $4 \mathrm{~cm}$, length $160 \mathrm{~cm}$ ) leading to a horizontal platform with a cardboard box in which for the mouse to hide. Two mirrors were positioned behind the rope, at an angle of $45^{\circ}$, to allow free view of the rope from all sides. Mice were trained to climb up and get onto the platform after placing them on the rope. The run of each animal was videorecorded in three consecutive trials for each time point. Afterward, average climbing speed was analyzed using segments of uninterrupted climbing (minimum $20 \mathrm{~cm}$, maximum $60 \mathrm{~cm}$ ).

Grid walking. The grid walking device consisted of an elevated metal grid (height $43 \mathrm{~cm}$, length $58.5 \mathrm{~cm}$, width $20 \mathrm{~cm}$ ) with a square $14 \times 14$ $\mathrm{mm}$ mesh (diameter of rungs $2 \mathrm{~mm}$ ). A mirror was fixed at a $45^{\circ}$ angle below the grid, allowing recording from the side and below. Animals were placed onto the grid and were allowed to freely explore for $3 \mathrm{~min}$. All forelimb errors of the left, mainly affected forepaw (of 50 randomly chosen steps) were scored and quantified. An error was counted when either the forelimb completely missed a rung (misplacement) or when the paw was correctly placed on the rung but then slipped off through the grid (slip).

Cylinder test. Mice were placed in a transparent Plexiglas cylinder (diameter $9.5 \mathrm{~cm}$, height $16 \mathrm{~cm}$ ), positioned in front of two mirrors angled $45^{\circ}$, to allow the observation of forepaw contacts from all sides (Shanina et al., 2006). Spontaneous rearing of each mouse was recorded for $5 \mathrm{~min}$, and the contacts for the left, right, or both paws simultaneously were analyzed. Placing asymmetry was calculated according to a previous publication (Whishaw, 2004): asymmetry $=[($ right $+0.5 \times$ both $) \times$ $\left.(\text { right }+ \text { left }+ \text { both })^{-1} \times 100\right] ; 50 \%$ means equilateral use, $>50 \%$ means hyper-reliance on the right forelimb, and $<50 \%$ hyper-reliance on the left forelimb. Paw placing was calculated as the number of times where the left paw made contact with the cylinder per times when the animal lifted both paws from the floor.

\section{Retrograde muscle tracing}

A group of 6 mice ( $n=2$, each muscle group) were used for retrograde muscle tracing with FastBlue (FB; $2 \%$ suspension in $0.1 \mathrm{M}$ phosphate buffer (PB) with $2 \%$ dimethyl sulfoxide, EMS-Chemie). Each animal received an injection in one muscle group on the left and another group on the right side of the body. Tracer was injected through small skin incisions into M. trapezius, M. pectoralis major, M. biceps brachii, M. triceps brachii, the forearm flexor muscles, and the forearm extensor muscles. Positions of labeled motorneurons were extracted from horizontal spinal cord sections (L.C.B., unpublished observations).

\section{Spinal C6-C7 unilateral, retrograde tracing}

A group of 16 animals were used for retrograde tracing $(n=9$ intact animals, $n=8$ animals $28 \mathrm{~d}$ after photothrombotic stroke). A laminectomy of vertebra C6 was performed to expose cervical spinal segments C6-C7. The animal was fixed in the stereotactic frame and two injections of $20 \mathrm{nl} \mathrm{FB}$ ( $2 \%$ suspension in $0.1 \mathrm{M} \mathrm{PB}$ with $2 \%$ DMSO, EMS-Chemie) were made on the left side of the spinal cord through local dura openings. A 33 gauge, $10 \mu$ l syringe (World Precision Instruments), driven by an electrical pump (World Precision Instruments) with a flow rate of 170 $\mathrm{nl} / \mathrm{s}$ was used. The first injection was done just caudal to the lamina of vertebra C5, $0.4 \mathrm{~mm}$ lateral to the midline and $0.8-1 \mathrm{~mm}$ below the spinal cord surface. After the injection, the needle was kept in place for 2 min to prevent backflow of tracer. The second injection was placed 0.3 $\mathrm{mm}$ caudal to the first injection. The tracer was allowed to be transported for $3 \mathrm{~d}$, before mice were perfused. For control, healthy age-matched female C57BL/6 mice were traced using the same setup.

\section{Anterograde tracing}

A group of 15 animals were used for anterograde tracing ( $n=8$ intact animals, $n=7$ animals $28 \mathrm{~d}$ after photothrombotic stroke). The animals were fixed in a stereotactic frame, the scalp was opened, and a craniotomy was performed over the left motor cortex. Dura was kept intact. Three injections of a $10 \%$ biotinylated dextran amine in $\mathrm{H}_{2} \mathrm{O}$ (BDA 10,000 molecular weight, Invitrogen) were made through local dura openings. Each $20 \mathrm{nl}$ injection was applied with a 33 gauge, $10 \mu \mathrm{l}$ syringe driven by an electrical pump with a flow rate of $6 \mathrm{~nL} / \mathrm{s}$. The coordinates were as follows: $0.5 \mathrm{~mm}$ rostral, $1.5 \mathrm{~mm}$ lateral to bregma; $0.5 \mathrm{~mm}$ rostral, $2 \mathrm{~mm}$ lateral to bregma; and $2 \mathrm{~mm}$ rostral, $1.5 \mathrm{~mm}$ lateral to bregma. Injections were made in a depth of $1 \mathrm{~mm}$ below the cortical surface. The needle remained in place for $2 \mathrm{~min}$ after each injection to avoid backflow of the tracer. After the last injection, the animal was sutured and removed from the stereotactic frame. The tracer was allowed to be transported for 1 week before the animal was perfused.

\section{Perfusion and tissue preparation}

All mice were terminally anesthetized with $3-5 \%$ isoflurane followed by injection of pentobarbital (i.p.; $300 \mathrm{mg} / \mathrm{kg}$ body weight, StreuliPharma). Animals were transcardially perfused with Ringer's solution (containing $10^{5}$ IU/L heparin, Roche; and $0.25 \% \mathrm{NaNO}_{2}$ ) followed by $4 \%$ phosphate- 

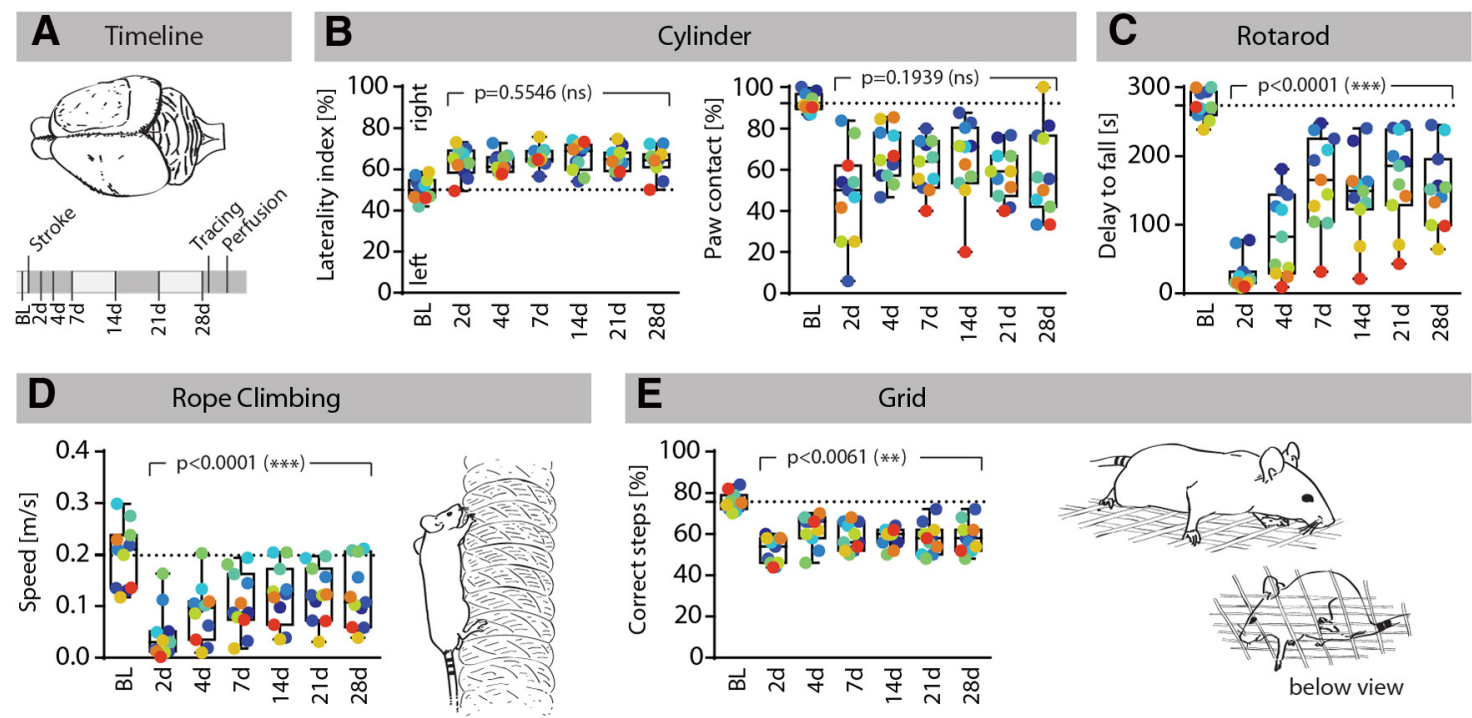

Figure 1. Partial recovery of proximal and distal motor functions after unilateral motor cortex stroke. $A$, Adult female $57 \mathrm{BL} / 6$ mice $(n=11)$ received a large unilateral photothrombotic stroke to the right hemisphere, depriving the left spinal hemicord of its main corticospinal input. Behavioral performance was tested periodically until $28 \mathrm{~d}$ after stroke. Animals were subsequently injected with the retrograde tracer $F B$ and $3 \mathrm{~d}$ later perfused. $\boldsymbol{B}$, Starting at $2 \mathrm{~d}$ until $28 \mathrm{~d}$ poststroke animals showed a preference to use the right paw for rearing in a cylinder. The ability to place the affected paw at the cylinder was deficient and did not recover (cylinder contacts per total amount of stand-up). C, Largely unable to stay on a rotating rod at $2 \mathrm{~d}$, function gradually returned throughout the testing period. From $7 \mathrm{~d}$ onward, performance stabilized at intermediate levels. D, Climbing up a rope requires forceful, controlled use of the distal and proximal fore and hindlimbs (drawing). Because of an initial paresis of the left forelimb, climbing ability was impaired. This is reflected in a deficient climbing speed. Function gradually recovered, entering a functional plateau between 14 and $28 \mathrm{~d}$. $\boldsymbol{E}$, The number of correct, first attempt steps with the left paw on the grid remained deficient, showing only limited recovery until $28 \mathrm{~d}$. When slipping through the mesh (drawing) at later time-points (i.e., $14 \mathrm{~d}$ onward), in contrast to the initial time after stroke, animals quickly retracted and adjusted the limb position (not quantified observation). Repeated-measures one-way ANOVA for $2 \mathrm{~d}$ to $28 \mathrm{~d}$, no post hoc testing; $n=11$.

buffered PFA solution containing $5 \%$ sucrose. The brain, including the whole spinal cord, was extracted and postfixed overnight in the same solution. After $24 \mathrm{~h}$, the tissue was transferred to a $30 \%$ sucrose solution in $0.1 \mathrm{M}$ PB.

\section{Quantification of retrograde tracing}

All FB-containing neurons were reconstructed into a standardized C57BL/6 mouse brain model using a technique to be described in detail (L.C.B., unpublished observations). Briefly, the tissue was embedded in a protein matrix (5 g/L gelatin, $380 \mathrm{~g} / \mathrm{L}$ chick egg albumin, and $200 \mathrm{~g} / \mathrm{L}$ sucrose in $0.1 \mathrm{M}$ PB, pH 7.4) that was cross-linked with glutaraldehyde (9 parts matrix-basis solution mist with 1 part $25 \%$ glutaraldehyde) and cut in $100 \mu \mathrm{m}$ horizontal sections on a vibratome (Leica VT1000S). Sections were mounted on Superfrost plus slides (Gerhard Menzel), glued onto one edge, and stored in $0.1 \mathrm{M} \mathrm{PB}$. After acquiring mosaic pictures of the whole section (Zeiss Axioskop 2 MOT Plus with motorized stage, $5 \times$ objective, AxioVision, Module MosaiX), pictures were aligned in Photoshop by means of anatomical landmarks (anterior commissure, red nucleus, the central branch of seventh cranial nerve, and decussation of pyramids). Fluorescently labeled cells were manually counted on each layer using Fiji (www.fiji.sc) and measured $x y z$ coordinates of each cell together with the landmark specifications exported. Brain size was normalized to a template, and brain midline was straightened by means of defined anatomical landmarks and trigonometric calculations.

Cell numbers were normalized so that each brain contained $10^{4}$ labeled neurons in the caudal brain (i.e., caudal to the red nucleus) to correct for minor variability in tracer efficiency. For this normalization, it was assumed that the overall number of spinal projecting cells from the hindbrain between intact and chronic animals remains approximately constant. Regions of interest were defined in accordance to previous publication (Liang et al., 2011). All data were extracted using customized MATLAB scripts (MATLAB Student Version R2011a, MathWorks).

\section{Quantification of anterograde tracing}

Embedding, cutting, and alignment were performed the same way as for the retrograde tracing. Fibers were visualized with a nickel-enhanced peroxidase reaction as described previously (Herzog and Brösamle, 1997). Mosaic images were acquired with a $10 \times$ objective. Tracercontaining bouton-like varicosities were quantified using a custom Fiji-based script. Briefly, varicosities were isolated through successive horizontal and vertical automatic local thresholding and mean filtering. Images were made binary at constant threshold, and varicosity-sized particles were counted and coordinates extracted and fitted into the standard brain model. All images of all groups were imaged and analyzed with the exact same parameters. Data were normalized based on blinded, manual counts of transversely cut fibers in the pyramidal decussation (counted at $40 \times$ using NeuroLucida). Normalization was done so that each animal had $10^{3}$ tracer-positive fibers in the decussation.

\section{Data analysis and statistics}

Behavioral tests were analyzed using one-way repeated-measures ANOVA over all postlesional time-points (GraphPad Prism Version 6.0, GraphPad Software). Anatomical data were compared using an unpaired, two-tailed, $t$ test between intact and chronic data of corresponding regions (GraphPad Prism). Correlation of recovered behavior and anatomical data was done for the behaviors that recovered significantly (rotarod, rope, and grid; scores at $28 \mathrm{~d}$ ) against anatomical regions that showed significant $(p<0.05)$ increases in cell counts. In addition, the cortical regions in the stroke-affected hemisphere were compared with the behavior. Goodness of correlation was judged by means of $R^{2}$ values from linear regression (GraphPad Prism). $R^{2}>0.81$ (i.e., $R$ values $<-0.9$ or $>0.9$ ) were considered as good correlation. For the $2 \mathrm{D}$ histograms group, averages of normalized data are presented. Variability is not shown in average cell distribution maps. $z$-scores are calculated as follows: $[z$-score $]=([$ individual cell count $]-[$ mean group cell count $]) \times[\text { group } S D]^{-1}$. Box plots show median as line, upper and lower quartile as box, and minimal and maximal value as whiskers. Bar graphs represent mean \pm SEM. Individual data points indicate individual animals; color-coded data points indicate the same animals in different graphs. Nonsignificant tendencies are indicated as (not significant but $p<0.1$ ). $p$ values $<0.05$ were considered to be statistically significant.

\section{Results}

\section{Motor behavior partially recovers after unilateral motor cortex stroke}

After right-sided photothrombotic ablation of the primary motor cortex in a cohort of female C57BL/6 mice $(n=11)$, motor recovery was monitored for 4 weeks (Fig. $1 A$ ). Rearing behavior 


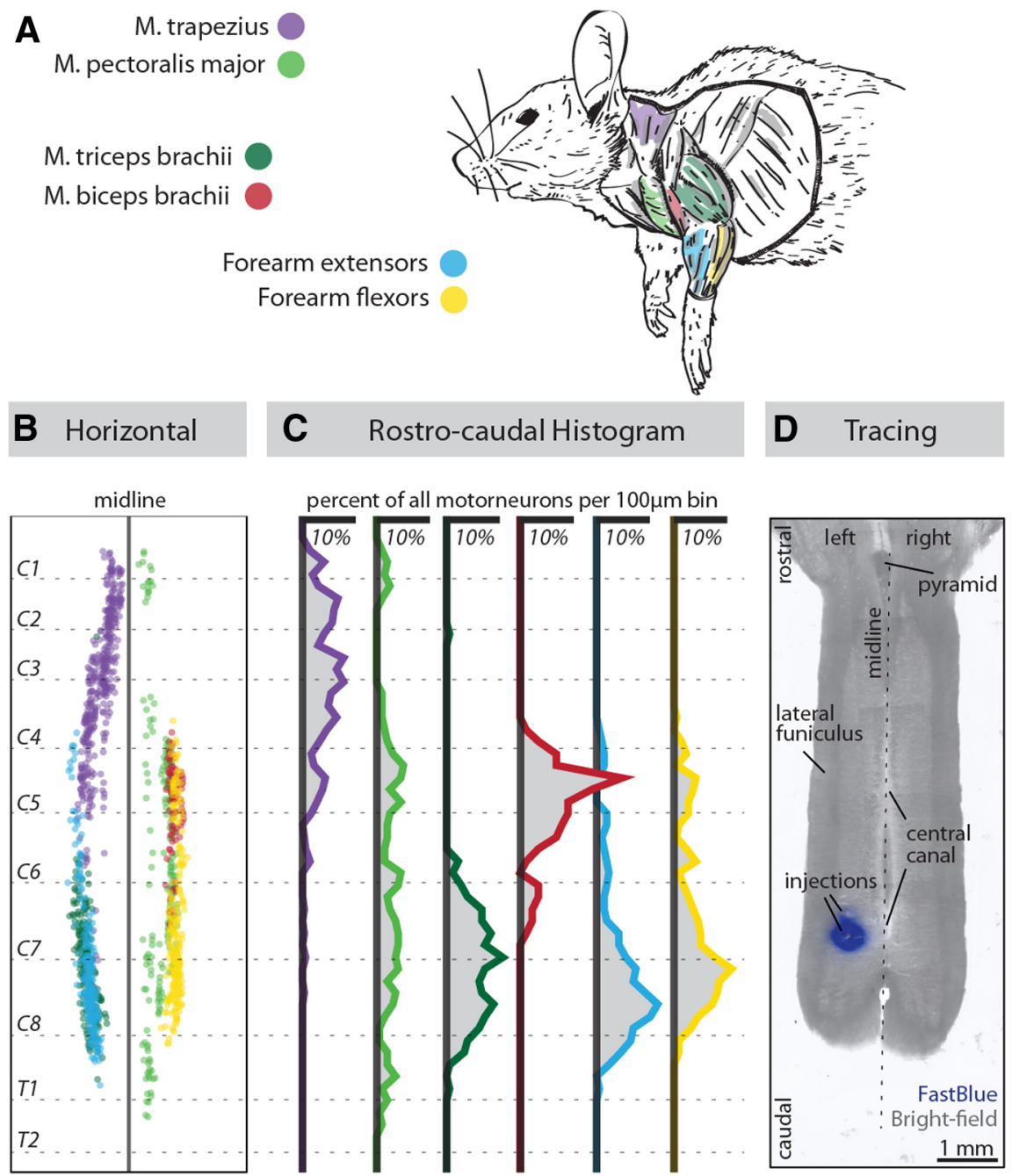

Figure 2. Motoneurons (MN) supplying proximal and distal forelimb muscles are located throughout the cervical enlargement. A, Proximal (M. trapezius, M. pectoralis major), upper arm (M. triceps brachii, M. biceps brachii), and lower arm muscles (paw flexors and extensors) were injected with $\mathrm{FB}$ ( $n=2$ animals, per muscle). $\boldsymbol{B}$, MN distribution along the rostrocaudal length of the spinal cord was mapped (composite view). C, M. trapezius MNs were most abundant in the rostral (C1-C5) spinal cord. M. pectoralis MNs spanned the whole length of the cervical spinal cord (medial and lateral cell column). M. biceps brachii MNs were mainly located in segments $\mathrm{C} 4$ and C5. M. trapezius and the lower arm muscle MNs were distributed in the C6-T1 segments. $\boldsymbol{C}$, Data are shown as percentage of total MN counted per muscle group per $100 \mu \mathrm{m}$ rostrocaudal bin. $D$, Cervical segments $C 6-C 7$ (i.e., vertebral segment (6) was chosen as the site of retrograde tracer (FB) injection to assess the plasticity of spinal projecting systems important for lower forelimb motor control. Horizontal spinal cord section (bright-field, gray) superimposed with FB fluorescent signal (blue).

in a transparent cylinder revealed an asymmetric preference to use the right forelimb that still received the majority of its cortical input from the left, intact motor cortex (Fig. 1B). From 4 to $28 \mathrm{~d}$ after stroke, many animals progressively reduced the use of the left, stroke-affected forepaw (Fig. $1 B$; paw contact; individual data points), suggesting a learned hyper-reliance on the less affected paw, a well-documented behavior seen in stroke subjects (Taub et al., 1994). When use of the left, stroke-affected paw was obligatory for a task (e.g., on the rotating rod) (Fig. $1 C-E$ ), performance gradually recovered, suggesting a functional recovery of the affected forepaw (Bury and Jones, 2002; Nakagawa et al., 2013; Zhao et al., 2013).

On the accelerating rotating rod, poor postural coordination led to an early falling after stroke. This recovered gradually over the subsequent 4 week period (Fig. 1C). Rope climbing requires extensor strength in the hindlimbs (pushing) and strength and dexterity in the forelimbs (grasping/holding; Fig. $1 D$, drawing). Climbing speed was impaired because of deficits in holding, releasing, and repositioning of the left forelimb (not quantified observation), whereby function of both hindlimbs appeared normal (Fig. 1D). On the grid (1 $\mathrm{cm}$ mesh size), left forelimb function was deficient. Functional stepping (i.e., the fraction of paw placements that did not miss or slip from the rung) recovered only incompletely (Fig. 1E). Initially, a slip resulted in a deep drop through the mesh (Fig. 1E, bottom) whereby at later timepoints (i.e., 1-4 weeks) slipping was followed by a swift repositioning movement until the left forepaw found a stance and the rung was grabbed indicating some recovery (not quantified observation).

In summary, despite functional deficits that persisted at 4 weeks after stroke and clear differences in the magnitude of recovery of individual animals (Fig. 1C-E; individual data points), a considerable overall recovery of upper arm and lowerforearm movements was observed.

\section{Motorneurons supplying upper arm and forearm are widely distributed in the caudal cervical spinal cord}

Retrograde labeling of motor neurons projecting to the M. trapezius and M. pectoralis major, the upper arm M. triceps and M. biceps brachii, and the forearm flexors and extensors ( $n=2$; each muscle) showed overall rostrocaudal gradients of innervation with more proximal muscles receiving input from more rostral cervical segments (Fig. $2 A-C$ ), in line with recent reports in mouse and rat (McKenna et al., 2000; Bácskai et al., 2013).

Cervical segments C6-C7, harboring parts of the triceps and forearm motorneuron pools, were injected with retrograde tracer ( $\mathrm{FB} 2 \%$ in $\mathrm{H}_{2} \mathrm{O} / \mathrm{DMSO}$ ) to detect plastic changes in the projections from the brain to the spinal cord that may correlate with the recovery of upper arm and forearm function (Fig. 2D).

\section{The most numerous projections to the cervical spinal cord} originate in the caudal brainstem

Intact animals (intact, $n=9$ ) and animals that had recovered from stroke for 4 weeks (chronic, $n=8$ ) were injected with FB in the left spinal hemicord at spinal level C6-C7 (Fig. 3). All FBlabeled neuronal cell bodies with projections into the traced, left hemicord, which was mainly affected by the stroke, were digitally reconstructed. Three-dimensional coordinates were fitted into a standard female mouse-brain model based on rostrocaudally distributed landmarks (see Materials and Methods).

Despite the crossed nature of some prominent motor systems (e.g., the corticospinal and rubrospinal system), the overall input into the left $\mathrm{C} 6-\mathrm{C} 7$ hemicord originates to similar degrees in 

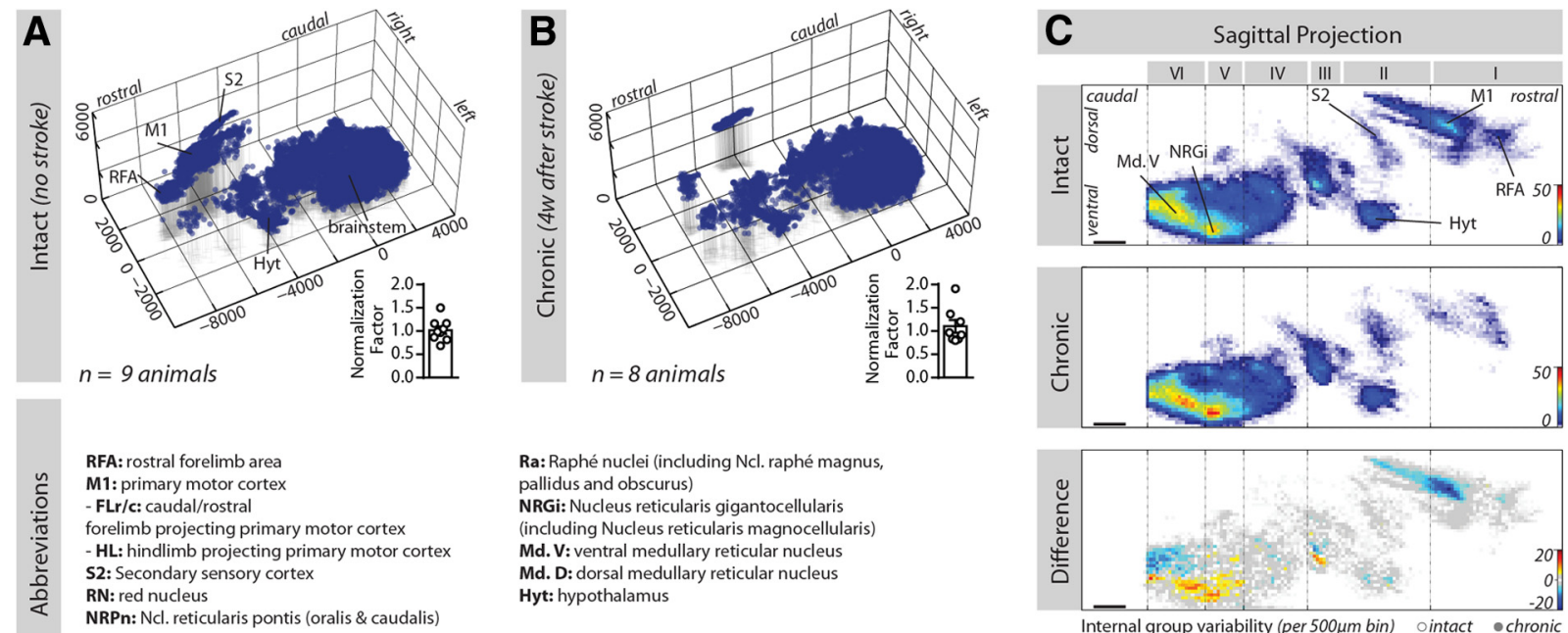

Ra: Raphé nuclei (including Ncl. raphé magnus, pallidus and obscurus)

NRGi: Nucleus reticularis gigantocellularis

(including Nucleus reticularis magnocellularis)

Md. V: ventral medullary reticular nucleus

Md. D: dorsal medullary reticular nucleus

Hyt: hypothalamus

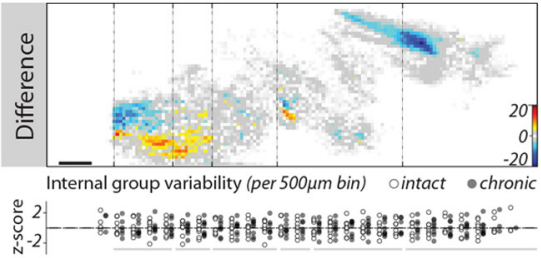

D

Horizontal Projection
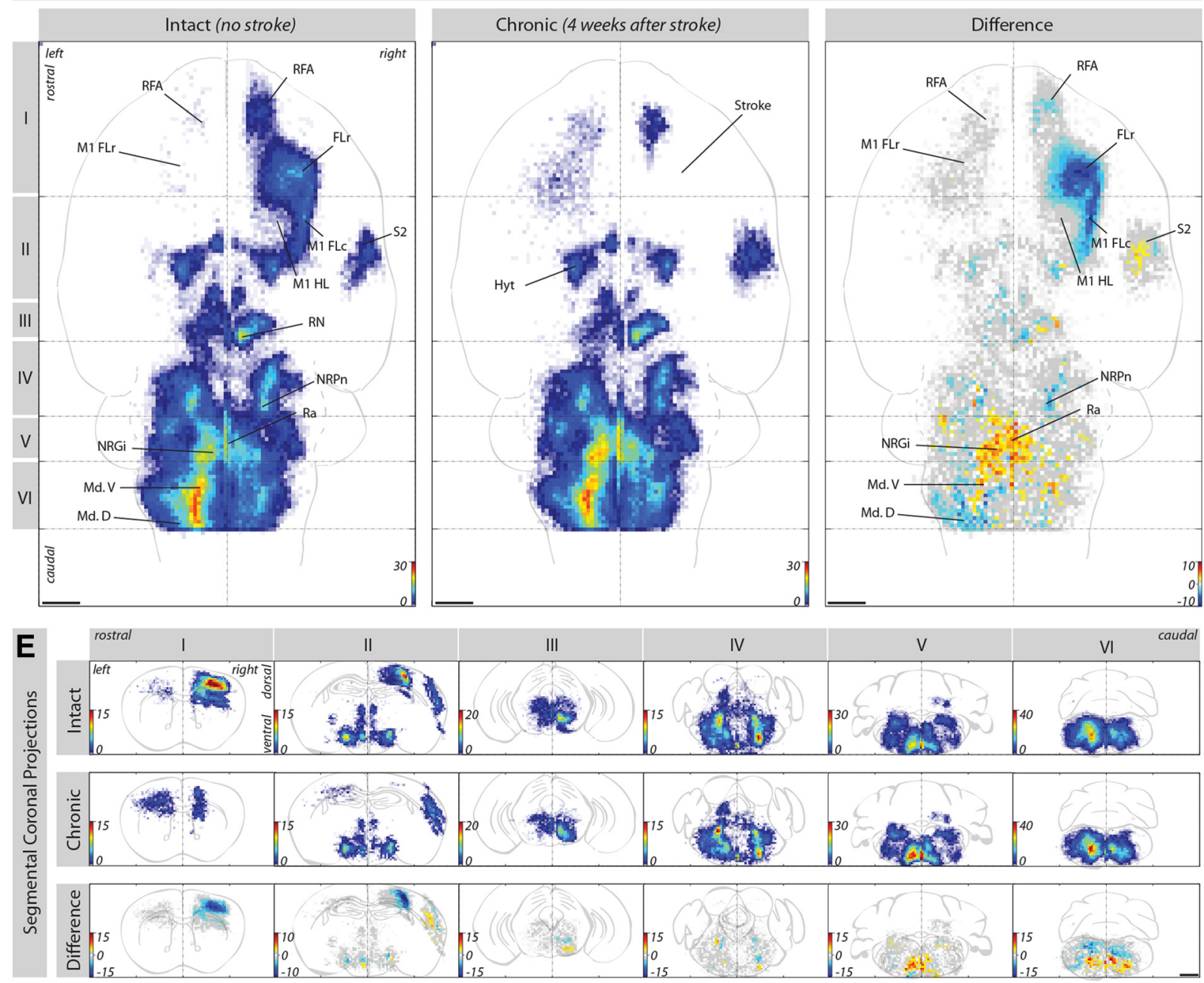

Figure 3. Anatomy of corticospinal and brainstem-spinal projections and their differential plastic reactions to stroke. $A, B$, Intact animals $(n=9)$ and animals that had recovered for 4 weeks after stroke (chronic, $n=8$ ) were injected with the retrograde tracer FB in the stroke-affected, left hemicord at spinal segment C6-C7. All FB-containing neurons were digitally reconstructed into a 3D mouse brain model. To correct for minor individual variance in tracing efficiency, cell counts were normalized (normalization factor: lower left corner). $\mathbf{C} \boldsymbol{E}$, Average cell distribution maps show the number of cells per individual $100 \times 100 \mu \mathrm{m}$ voxels (average of all animals per group; dimension orthogonal to the plain of view is collapsed). Difference maps represent the difference of cell numbers per individual $100 \times 100 \mu \mathrm{m}$ voxel projection between intact and chronic stroke animals. In difference maps, cold colors represent a decrease; warm colors represent an increase of labeled cell bodies from the intact to the chronic group. $\boldsymbol{E}, \mathrm{I}-\mathrm{VI}$, Coronal projections show the cell distribution in five rostrocaudal segments $(\boldsymbol{C}, \boldsymbol{D})$. $C$, Maps represent the prominent loss of cells in the lesioned cortex that had projections to the contralesional spinal cord at spinal level C6-C7 (blue in difference map). Two prominent plastic hotspots are seen in the brainstem: one just rostral to the inferior olive (segment V) in the ventral medulla and one more caudally, $\sim 500 \mu \mathrm{m}$ more dorsal (segment VI). In the dorsal aspects of the caudal medulla oblongata, (Figure legend continues.) 
both halves of the intact brain. This is the result of the brainstemspinal projections that show an ipsilateral projection dominance (Fig. 3D). In intact animals, the left half of the brain (i.e., the same side as the tracer injection) contained 53\%, the contralateral, right half $47 \%$ of all labeled neurons. In terms of brain regions, $58 \%$ of all spinally projecting neurons were located in the medulla oblongata, $16 \%$ in the pons, and only $13 \%$ in the cortex of intact animals. Labeled neuronal cell bodies were detected in areas previously described to project to the spinal cord (Liang et al., 2011).

After stroke, contralesional corticospinal neurons reinnervate the affected hemicord and form a mirrored cortical map

The photothrombotic stroke induced an efficient loss of neurons in the right cortical hemisphere (Fig. 3C-E: difference histogram; blue in segments I, II). Despite a small population of spared neurons in the medial, rostral forelimb area (Figs. 3D,E, segment I and $4 G, 50 \%$ sparing), almost all of the corticospinal neurons in the caudal motor cortex were ablated (Fig. $4 F:<1.2 \%$ sparing).

As in previous studies (Ueno et al., 2012), neurons in the spared sensorimotor cortex, contralateral to the stroke, markedly increased their projections into the left hemicord over time (Fig. $3 D$ ). The shape of the newly appeared map of cells mirrored the intact motor cortex. In the intact primary motor cortex, the rostral forelimb area made up $16 \%$ of the cells; in the de novo formed, mirrored map, the rostral forelimb area contained $25 \%$ of the cells retrogradely labeled from the C6-C7 spinal cord. Hence, despite the partial sparing of the rostral forelimb area, the de novo formed map is composed to a similar proportion by rostral forelimb area neurons. Considering the total number of contralesional cortical neurons projecting to the ipsilateral strokedenervated hemicord, only $13.2 \%$ of the initial cell numbers were found. Hence, the functional reconnection of the contralesional motor cortex to the left, stroke-affected hemicord by this direct corticospinal projection is likely to remain incomplete.

Despite observed contralesional motor cortex sprouting (i.e., de novo formed map), the secondary sensory cortex (S2) did not react with a comparable response (Figs. $3 D$, E, segment II and $4 K)$, speaking against an overall uniform cortical growth response. The right secondary sensory cortex, adjacent to the stroke but fully spared, reacted with a 1.4-fold increase of its C6-C7projecting cells, adding to previous reports that adjacent, ipsilesional, spared cortical areas may sprout in response to stroke (Nudo et al., 1996; Starkey et al., 2012).

$\leftarrow$

(Figure legend continued.) a decrease of FB containing neurons is indicated (segment VI). D, Comparing intact and chronic animals reveals that the rostral forelimb area was partially spared. A widespread sprouting response of cortical cells, contralateral to the stroke, was seen (segments I and II). These cells, with a de novo ipsilateral projection, appeared as mirrored image of the intact primary motor cortex. In the medullary brainstem, the two plastic hotspots $(C)$ are seen primarily on the left side, contralateral to the stroke. At the midline, the raphe nuclei contain more cells projecting into the stroke-affected hemicord after stroke (segment V). $\boldsymbol{E}, \mathrm{A}$ detailed view of the rostrocaudal segments I-VI reveals an increase of cells in the secondary sensory cortex (segment II) and in the left, contralateral, lateral vestibular nucleus (segment V) after stroke ( $\boldsymbol{C}$, internal group variability). Distribution of individual animals in both groups relative to the group mean are comparable, showing that average cell distribution maps are not dominated by statistical outliers in either group. This is illustrated by the cell counts per $500 \mu \mathrm{m}$ rostrocaudal segment for each animal, which are expressed as $z$-score (i.e., cell count $=$ group mean $+z$-score $\times S D$ of all animals within the corresponding group; see Materials and Methods).

\section{No significant formation but partial weakening of diencephalic, mesencephalic, and pontine spinal C6-C7 projections}

Cells projecting to the spinal cord from subcortical regions rostral to the pons did not sprout into the stroke-affected, left hemicord (Figs. 3E, segments II-IV and $4 L-R$ ). The left hypothalamus (Fig. 4L), comprised of several subregions (Liang et al., 2011), and the right, nucleus reticularis pontis (Fig. 4Q), comprising the oral and caudal subnucleus, showed a slight decrease of labeled cells to $\sim 80 \%$ of intact values in the chronic stroke animals. In the right mesencephalic tegmental areas (Fig. $4 \mathrm{~N}, \mathrm{O}$ ), including the mesencephalic reticular formation, the colliculi, and parts of the functionally characterized mesencephalic locomotor region (Liang et al., 2012), only $\sim 60 \%$ of cells projecting to the left spinal segments $\mathrm{C} 6-\mathrm{C} 7$ were retrogradely labeled in the stroke compared with intact animals. The red nucleus, functionally closely related to the motor cortex (Kennedy, 1990), did not show sprouting into the stroke-affected hemicord (Fig. $4 M$ ). No changes were seen in the area of the locus ceruleus (Fig. 4P).

\section{Weakening of parvocellullar and dorsal medullary reticular nucleus projections to the stroke-affected hemicord}

In chronic stroke compared with intact animals, fewer labeled neurons were found in the lateral aspects of the rostral medullary reticular formation (Fig. 3D, E, segment IV). This area comprises the Ncl. reticularis parvocellularis (Fig. $5 H$ ). Neuron numbers bilaterally decreased to $\sim 80 \%$ of intact values. More caudally, in the dorsal medullary reticular nucleus on the left side, contralateral to the stroke, labeled neuron numbers decreased to $83 \%$, on the right side to $63 \%$ of intact values.

\section{Raphe nuclei and the lateral vestibular nucleus increase their left spinal projections after stroke}

Three loci in the nonreticular medullary brainstem were found to increase their projections to the left hemicord after the rightsided motor cortex stroke: the serotonergic raphe nuclei on both sides located immediately at the sagittal midline of the medulla (Figs. 3D, E, segment $\mathrm{V}$, and $5 C$ ), the lateral vestibular ncl. on the left side, ipsilateral to the stroke-affected hemicord (Fig. $5 F$ ), and the right-sided oral part of the spinal trigeminal nucleus (Fig. $5 N$ ). The raphe-spinal projection nuclei, including Ncll. raphe obscurus, pallidus, and magnus, are one of two main sources of supraspinal serotoninergic projections to the spinal cord, the other being the lateral part of Ncl. reticularis gigantocellularis (also called lateral paragigantocellular nucleus) (Liang et al., 2011). Serotonergic fibers are known to retain considerable growth capacities even in the adult CNS (Nygren et al., 1974; Cheng and Olson, 1995).

The lateral vestibular ncl., linked to postural reflexes, increased its projections to the left spinal C6-C7 hemicord by 1.29-fold (Fig. 5F). Functional implications of this increased projection (e.g., with respect to progressive poststroke flexor-tone) remain to be elucidated (Bach and Magoun, 1947; Welmer et al., 2010). The oral spinal trigeminal nucleus on the right side on average increased its projections to the left, stroke-affected hemicord whereby this response was variable across individual animals and absolute numbers of labeled cells remained low (Fig. 5O; individual data points).

Increased projections from the medullary reticular formation into the stroke-affected left $\mathrm{C} 6-\mathrm{C} 7$ spinal cord

Two loci in the reticular formation of the ventral medulla oblongata were found to strongly increase their number of left spinal 


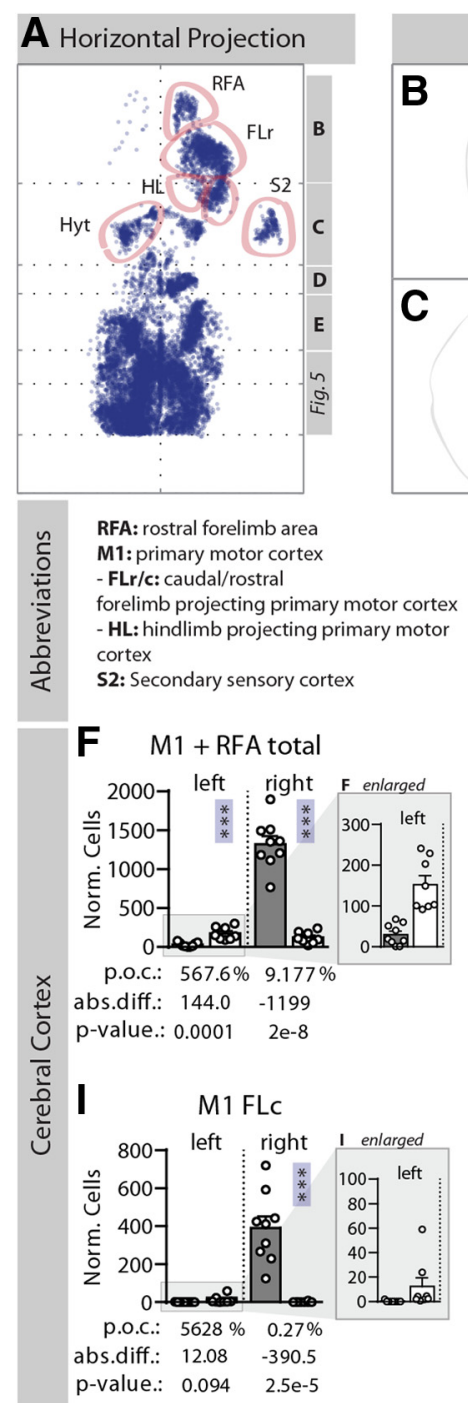

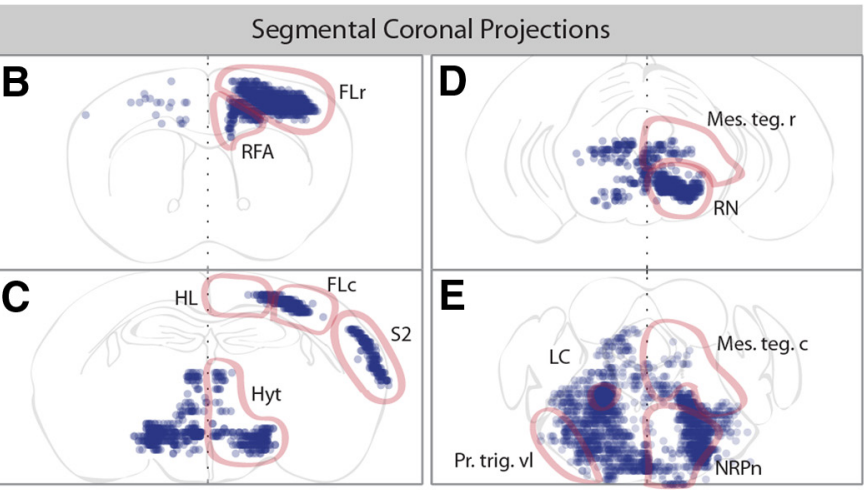

Hyt: hypothalamic areas RN: red nucleus

Mes. teg. $\mathbf{r} / \mathbf{c}$ : rostral/caudal mesencephalic tegmental areas LC: Locus coeruleus

NRPn: Ncl. reticularis pontis (oralis \& caudalis)

Pr. trig. vl: principal sensory trigeminal p.o.c.: percentage of control nucleus, ventro-lateral
G

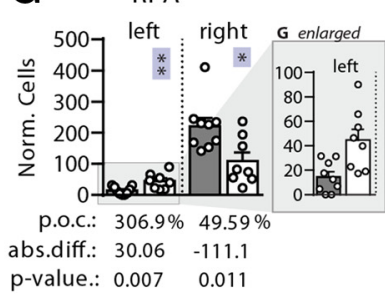

J

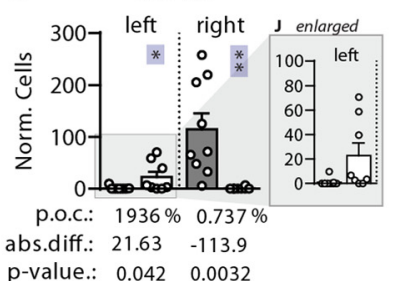

H M1 FLr

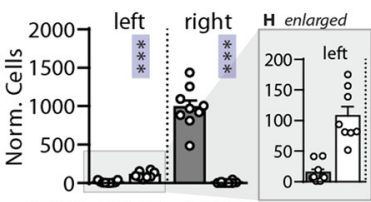

p.o.c.: $711.9 \% 1.119 \%$

abs.diff.: $92.32 \quad-974.4$

p-value.: $2 \mathrm{e}-5 \quad 4 \mathrm{e}-8$

K $\quad$ S2

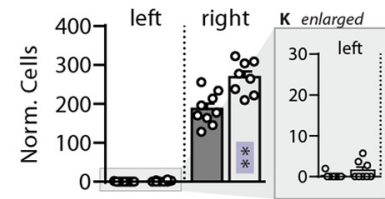

p.o.c.: $694.0 \% \quad 143.3 \%$

abs.diff.: $1.298 \quad 81.24$

p-value.: $0.1175 \quad 0.0012$

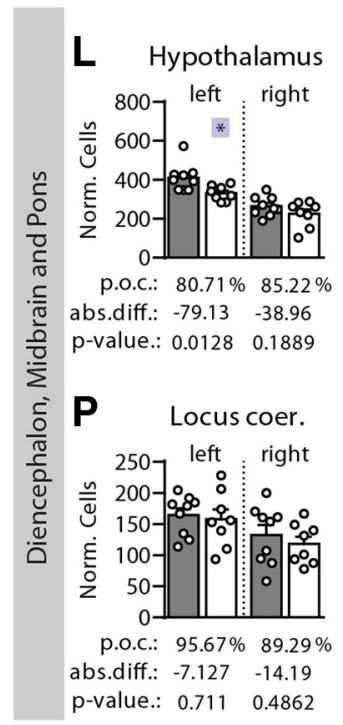

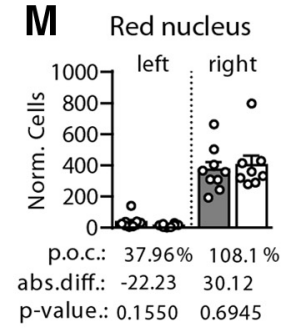

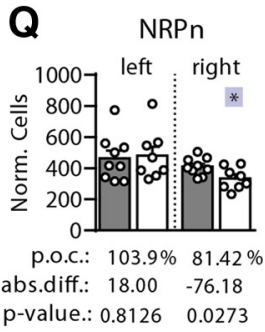

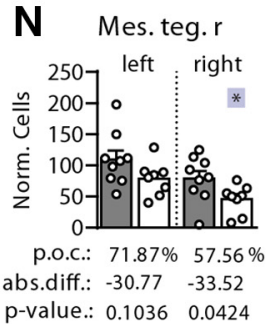

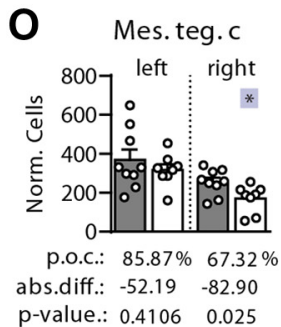

R Pr.trig.vl

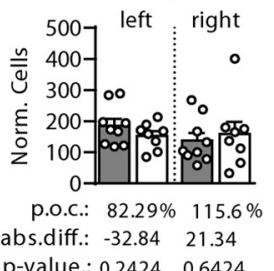

$\square$ intact

chronic ( 4 w after

Figure 4. Quantification of projection changes of cortex and upper brainstem to the stroke-affected spinal hemicord. Eleven separate cortical $(\boldsymbol{A}-\boldsymbol{C})$ and subcortical ( $\boldsymbol{C}-\boldsymbol{E})$ regions projecting to segments $\mathrm{C} 6$ - $\mathrm{C}$ of the stroke-affected hemicord were analyzed in intact (gray bars) and chronic stroke (white bars) animals. $\boldsymbol{F}-\boldsymbol{R}$, Left and right sides of the brain were analyzed separately (i.e., left being contralateral to the stroke, but ipsilateral to the deficient forepaw and the tracer injection). $\boldsymbol{F}$, The stroke spared only $10 \%$ of the sensory motor cortex on the ipsilesional hemisphere (G) because of a $\sim 50 \%$ sparing of the rostral forelimb area (RFA). A significant number of de novo left cervical spinal projections originate from the unlesioned cortical hemisphere $(\boldsymbol{F}$, total), in particular from the rostral part of the main forelimb projecting area $(\boldsymbol{H} ; \mathrm{M} 1 \mathrm{FLr})$ along with a considerable population in the RFA $(\boldsymbol{G})$. De novo projections from the caudal portion of the main forelimb projecting area $(I, M 1 F L c)$ did not form consistently in all animals. $J$, De novo projections from the main hindlimb projecting cortex (M1 HL) increased significantly, but not consistently, in all animals $(\boldsymbol{J}$, left, individual data points). $\boldsymbol{K}$, The corticospinal projections from the right secondary sensory cortex (S2), being spared by the stroke, also increased. (Figure legend continues.) 


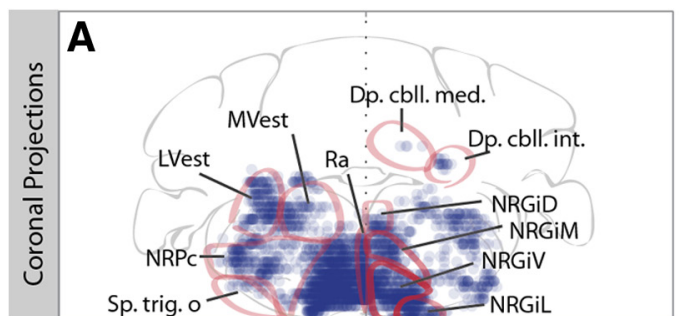

Ra: raphé nuclei

Dp. cbll. med.: medial deep cerebellar ncl. Dp. cbll. int.: interposed deep cerebellar ncl. LVest: lateral vestibular ncl.

MVest: medial vestibular ncl.

NRPa: ncl. reticularis parvocellularis

Sp. trig. o/c: spinal trigeminal nuclei (oral \& cauda)
NRGi: ncl. reticularis gigantocellularis - NRGiD: dorsal part of NRGi - NRGiM: intermediate part of NRGi - NRGiV: ventral part of NRGi (including $\mathrm{Ncl}$. reticularis magnocellularis) - NRGiL: lateral part of NRGi

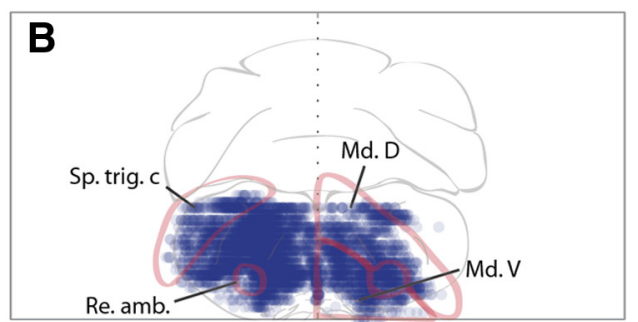

Re. amb.: ncl. retroambiguus Md. D: dorsal medullary reticular ncl. Md. V: ventral medullary reticular nc

p.o.c.: percentage of control abs.diff.: absolute difference
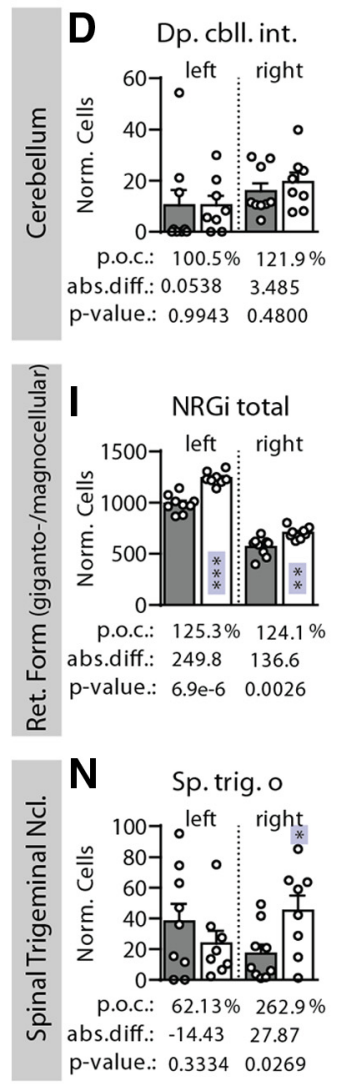

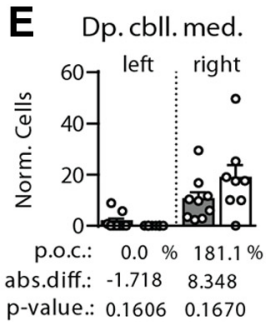

J
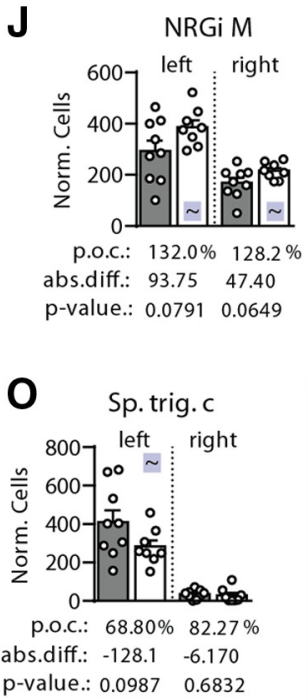

F Lateral vestibular ncl.
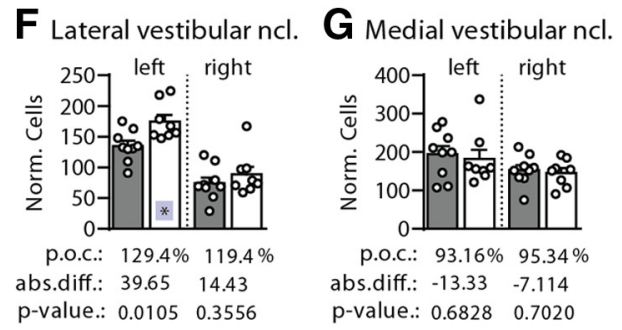

p.o.c.: $93.16 \% 95.34 \%$ abs.diff.: $-13.33 \quad-7.114$ p-value.: $0.6828 \quad 0.7020$

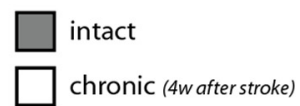

C

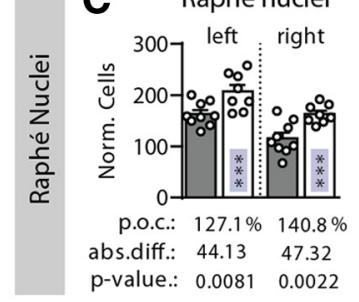

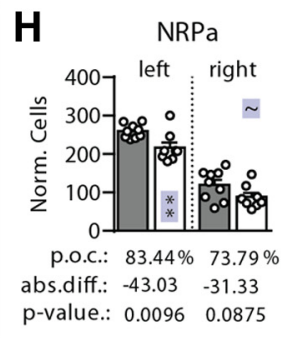
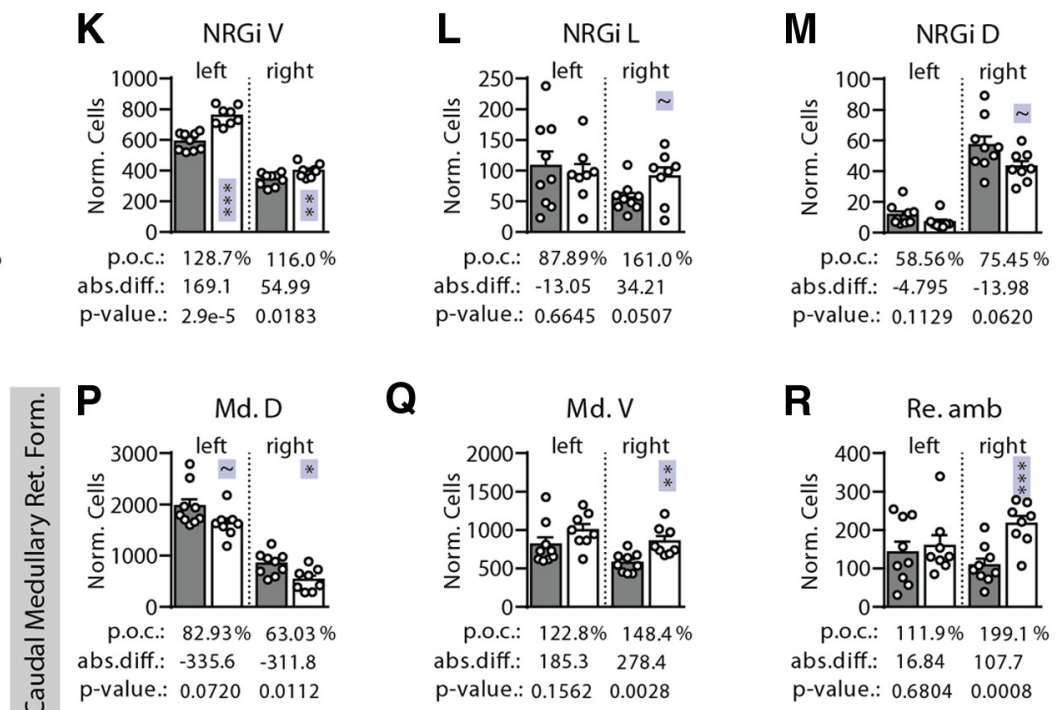

$\mathbf{R}$

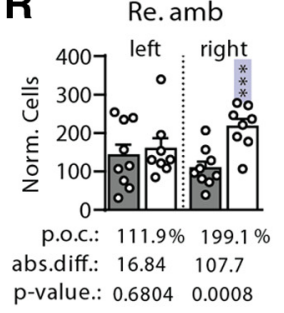

Figure 5. Quantification of projection changes of the cerebellar and lower brainstem nuclei. Fifteen separate (6-C7-projecting areas in the cerebellum, the rostral medulla oblongata (A), and the caudal medulla $(\boldsymbol{B})$ were analyzed in intact (gray bars) and chronic stroke (white bars) animals $(\boldsymbol{C}-\boldsymbol{R})$ (right side ipsilateral to the stroke). $\boldsymbol{C}$, The serotonergic raphe nuclei (i.e., raphe obscurus, pallidus, and magnus) located on both sides immediately at the sagittal midline increased their projection into the left (i.e., stroke-affected hemicord). D, E, Unchanged, weak projections from the deep cerebellum. $\boldsymbol{F}$, The left, lateral, but not the medial $(\mathbf{G})$, vestibular ncl. showed increased retrograde labeling in chronic animals. $\boldsymbol{H}$, Cell counts decrease in Ncl. reticularis parvocellularis after stroke. I-M, The most numerous de novo projections into the left (6-C7 spinal hemicord were found from the Ncl. reticularis gigantocellularis $(\boldsymbol{I} ; \mathrm{NRGi})$, in particular, from the ventral aspects of the nucleus ( $\boldsymbol{K} ;$ NRGiV, including Ncl. ret. magnocellularis or gigantocellularis pars $\alpha$ ). The more dorsal, intermediate NRGi showed a tendency (see $p$ values) to a similar, $\sim 1.3$-fold increase $(J$; NRGiM). $L$, The right, lateral gigantocellular ncl. (including the lateral paragigantocellularncl.) tended to increase its left spinal projections by 1.6 -fold $(p=0.0507) . M, 0$ nly a decrease in the spinal projection was present in the dorsal aspects of NRGiD. $N, 0$, Some plasticity was seen in the oral part of the spinal trigeminal nucleus. $\boldsymbol{P}-\boldsymbol{R}$, In the caudal, medullary reticular formation, the considerably fewer $(6-C 7$-projecting cells were found in the dorsal aspects in chronic animals $(\boldsymbol{P})$. The ventral medullary ret. ncl., like the more rostral ventral ret. ncll., significantly strengthened its left spinal projections (Q). The ipsilesional ncl. retroambiguus doubled its (6-C7 projection. $\mathbf{C}-\boldsymbol{R}$, p.o.c., Percentage of control (i.e., chronic as \% of intact); abs.diff., absolute difference (i.e., [chronic] - [intact]). Unpaired, two-tailed $t$ test: intact $(n=9)$ versus chronic $(n=8)$. $\sim$ Not significant (but $p<0.1) .{ }^{*} p<0.05$. ${ }^{* *} p<$ 0.01. ${ }^{* *} p<0.001$.

(Figure legend continued.) $\boldsymbol{L}-\boldsymbol{R}$, In the diencephalon, mesencephalon, and pons, there were no areas significantly strengthening their projections into the left hemicord. Several of these regions displayed a slight (i.e., to $60-80 \%$ of control) decrease of left spinal projecting neurons. $\boldsymbol{M}$, The red nucleus, functionally closely related to the cortex, showed no stroke-induced changes of projections. $\boldsymbol{F}-\boldsymbol{K}$, Insets, Left cell counts enlarged for better visibility. F-R, p.o.c., Percentage of control (i.e., chronic as \% of intact); abs.diff., absolute difference (i.e., [chronic] - [intact]). Unpaired, two-tailed $t$ test: intact $(n=9)$ versus chronic $(n=8) .{ }^{*} p<0.05 .{ }^{* *} p<0.01 .{ }^{* * *} p<0.001$. hemicord-projecting cells: one just rostral to the rostral end of the inferior olive (Fig. 3C,E, segment $\mathrm{V}$ ) and the other more caudally, just caudal to the rostral end of the inferior olive, $\sim 0.5 \mathrm{~mm}$ more dorsal and to the side (Fig. 3C-E, segment VI). This increase of labeled cells was most pronounced on the left side, ipsilateral to the stroke-affected hemicord, contralateral to the stroke, but also seen on the right side (Fig. 3D, E, segments $\mathrm{V}, \mathrm{VI}$ ). 
The more rostral of these areas comprises the ventral and intermediate aspects of the medullary nucleus reticularis gigantocellularis (NRGi; Fig. 5A). With an overall 1.25 increase of labeled neurons in the left and 1.24-fold increase in the right half of this nucleus, NRGi on average contained 386 neurons with a stroke-induced, de novo projection to C6-C7 left, stroke-affected hemicord (Fig. 5I,J-M). The majority of these de novo left projections come from the ventral part of NRGi (i.e., the parts also known as $\mathrm{Ncl}$. ret. magnocellularis or $\mathrm{Ncl}$. ret. gigantocellularis pars $\alpha$ ) (Fig. $5 K$ ).

The more caudal of the two plastic regions in the medullary reticular formation was located within the ventral medullary reticular nucleus, at the border region between the ventral and the dorsal medullary reticular nucleus (Fig. 3C,E, segment $\mathrm{VI})$. This area included the $\mathrm{Ncl}$. retroambiguus (Figs. 3E, 5B). The ventral medullary reticular nucleus is anatomically the caudal continuation of the NRGi (Fig. $3 D$ ). With a 1.22-fold increase of labeled cells on the left (that did not reach significance, Fig. 5Q, $p$ value) and a 1.48-fold increase of cells on the right, the ventral medullary reticular nucleus contained on average 464 neurons with a strokeinduced de novo projection to the left C6-C7 hemicord (Fig. 5Q). The area of the $\mathrm{Ncl}$. retroambiguus, which here may include few cells from the intermediate medullary reticular nucleus (Liang et al., 2011), was seen to strongly increase its projections from the right nucleus to the left spinal hemicord (1.99-fold; 108 neurons with de novo left spinal projection; Fig. 5R).

\section{Plastic changes of the \\ corticobulbar projections}

The anterograde tracer BDA was injected into the spared, left motor cortex of intact and chronic stroke mice ( $n=8$ and $n=7$, respectively), and the density of boutonlike varicosities was quantified in the different brainstem areas (Fig. 6A,B). The corticobulbar projection appeared strongly bilateral, corresponding to earlier descriptions (Valverde, 1962). Whereas smaller, mostly positive changes in response to the stroke were seen in many nuclei, a large, $\sim 1$.6-fold increase in cortical input was present in the rostral medullary reticular formation, in areas of the ventral Ncl. ret. gigantocellularis, and in the raphe nuclei (Fig. $6 C, D$ and Fig. $6 F, G$, respectively).

The left, ventral Ncl. ret. gigantocellularis is located dorsal to the pyramidal tract originating from the left motor cortex. Corticoreticular and corticoraphe projections branch off dorsally from the tract to innervate their medullary targets. Hence, the medullary brainstem, in addition to the sparse direct, ipsilateral motor-corticospinal tract, is one potential relay site for cortical control over the ipsilateral side of the body.

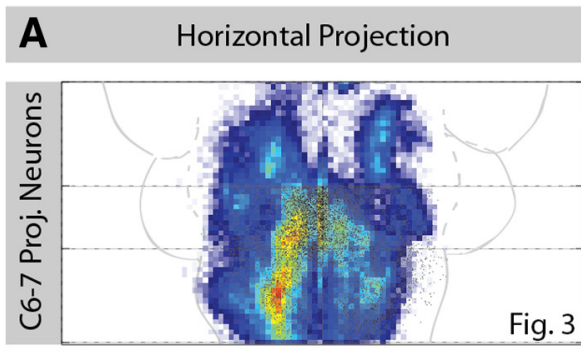

\section{B Coronal Projection (Medulla obl.)}
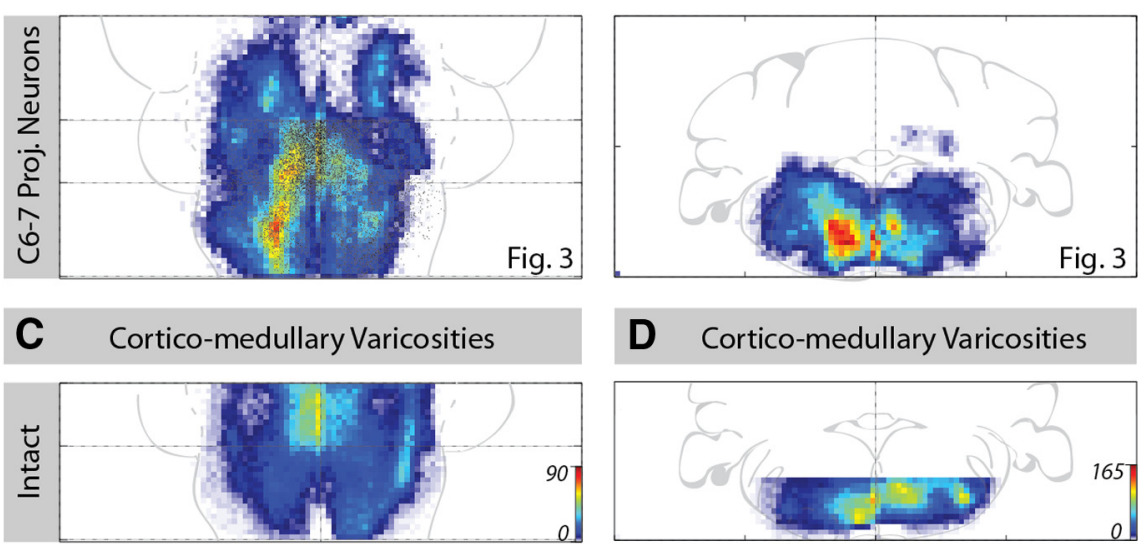

\section{Cortico-medullary Varicosities}
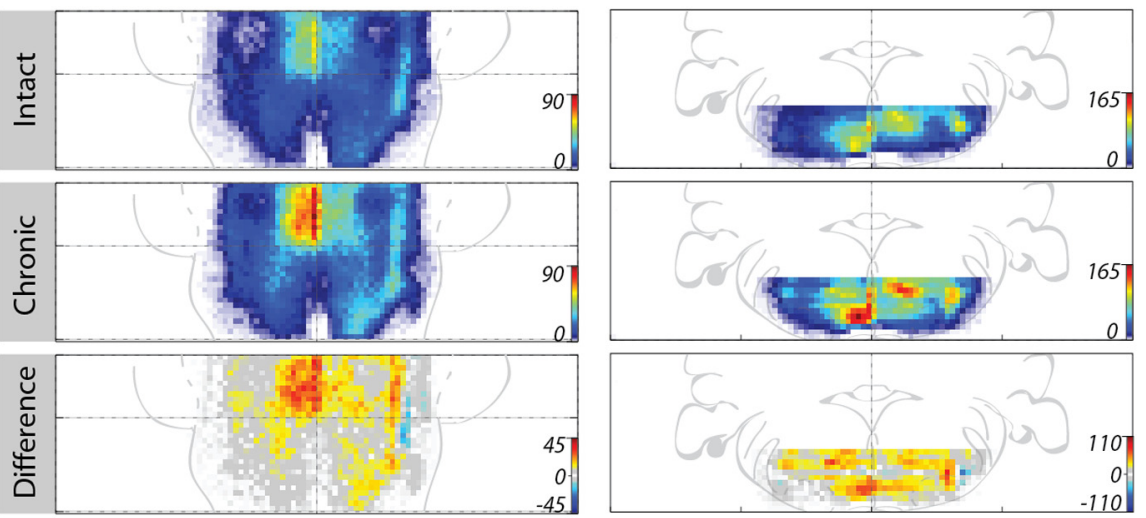

E Norm. Fact.

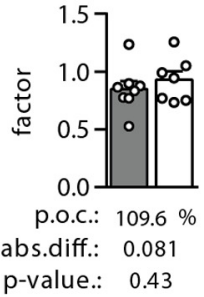

$\mathbf{F}$

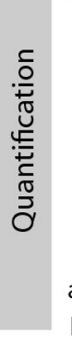

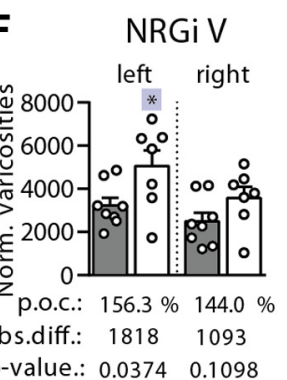

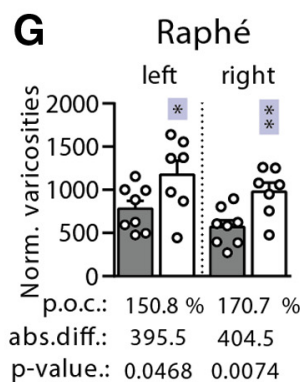

Figure 6. Plastic changes of corticobulbar projections from the spared, contralesional cortex. $\boldsymbol{A}$, Horizontal distribution map of C6-C7-projecting cells (same as Fig. 3D; segments V, Vl; chronic animals) with superimposed corticobulbar varicosities. B, Coronal density map of corticobulbar terminals shows strengthening of corticoreticular and corticoraphe projections from the contralesional motor cortex to the left, ipsilateral brainstem. Areas of increased innervation correlate with the strongly spinal projecting roups have comparable tracings and normalization factors. $\boldsymbol{F}, \mathbf{G}$, A significant, 1.5- to 1.7-fold increase of corticobulbar varicosities in the left ventral $\mathrm{Ncl}$. ret. gigantocellularis (i.e., including $\mathrm{Ncl}$. ret. magnocellularis or gigantocellularis pars $\alpha$ ) and the raphe nuclei on the sagittal midline (i.e., raphe obscurus, pallidus, and magnus). Unpaired, two-tailed $t$ test: intact $(n=8)$ versus chronic $(n=7) .{ }^{*} p<0.05$. ${ }^{* *} p<0.01$.

Functional recovery after one-sided stroke depends in part on the intact, contralateral motor cortex

The functional recovery observed after the right-sided motor cortex stroke (Fig. 1) was largely abolished by a second, left-sided photothrombotic stroke (second stroke) that was induced 4 weeks after the initial, right stroke (Fig. 7). Postural coordination, required to stay on the accelerating rotating rod, had partially recovered after the first stroke. After the second stroke, performance was, and remained, deficient in all but one animal (Fig. 7B, individual data points).

Paw placement asymmetry during rearing in the cylinder, which persisted throughout the time of recovery from the first stroke, returned back to equilateral use after the second stroke. However, the paw placing movement was greatly deficient after the second stroke, even more so than after the first stroke (Figs. 1B, 7C). The subsequent increase of paw contacts was 
A Timeline
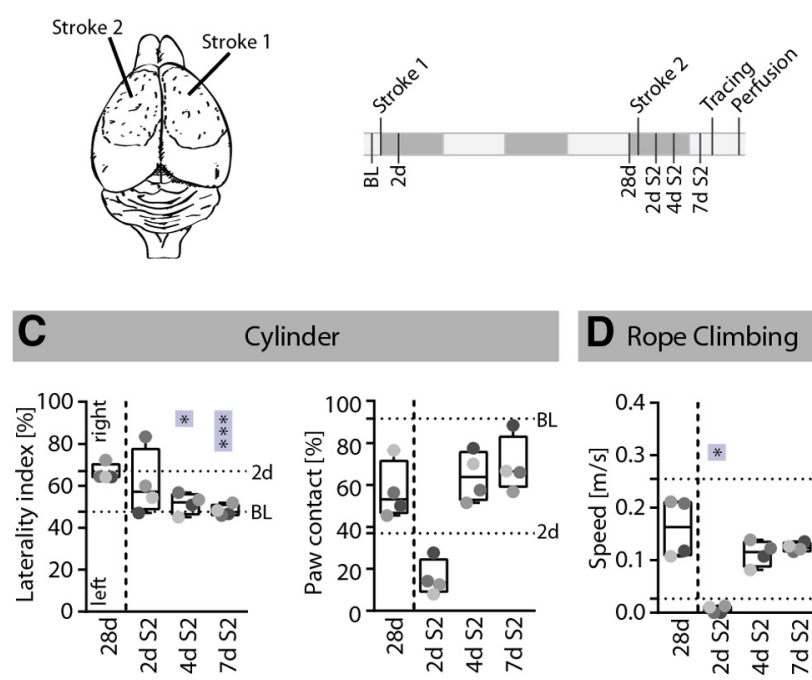

\section{Cylinder}

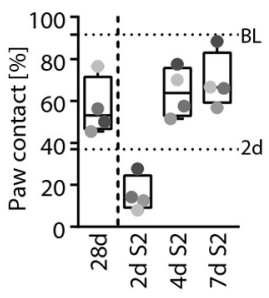

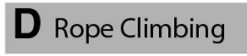

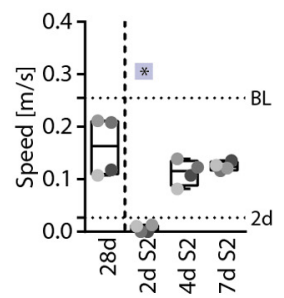

Figure 7. Recovery of function is dependent on the intact, contralateral cortex as shown by sequential, bilateral motor cortex stroke. A, Animals received a one-sided photothrombotic stroke (right, stroke 1), were allowed to recover for 4 weeks and then given a second stroke (left, stroke 2) leading to a complete, bilateral ablation of the primary motor cortex. $\boldsymbol{B}-\boldsymbol{E}$, Behavior was assessed before (baseline $[\mathrm{BL}])$ and after the first stroke $(2 \mathrm{~d})$ and before $(28 \mathrm{~d})$ and after the second stroke $(2,4,7 \mathrm{~d} \mathrm{S2})$. Dotted, horizontal line indicates mean performance at BL and $2 \mathrm{~d}$. Dashed vertical line indicates time of stroke 2. $\boldsymbol{B}$, Having partially recovered the ability to stay on a rotating rod performance is heavily deficient after the second stroke and remains deficient for all but one animal (see individual data points). C, Rearing asymmetry in the cylinder changed back to a symmetrical behavior because of the now bilaterally deficient paw placement ability. The ability to place the left (i.e., affected by stroke 1) forelimb to the cylinder wall was almost fully deficient initially after the second stroke (likewise the right paw; data not shown). Placing of the paws to the cylinder wall returned $4 \mathrm{~d}$ after stroke 2, whereby the firm placement of the paw was switched to a compensatory pawing/digging movement at the cylinder wall (data not shown). D, Rope climbing speed was strongly deficient after stroke 2, whereby function returned later on. $\boldsymbol{E}$, Functional stepping on the grid, having recovered only poorly after stroke 1 , was minimally affected by stroke 2 . Repeated-measures one-way ANOVA, post hoc testing: Dunnett's multiple comparison to $28 \mathrm{~d} ; n=4 .{ }^{*} p<0.05 .{ }^{* *} p<0.01 .{ }^{* *} p<0.001$.

the result of a pawing/scratching movement at the cylinder wall, which was used to functionally compensate for the paw placement deficit.

Rope climbing, which had recovered partially after the first stroke, was again strongly deficient after the second stroke (Fig. $7 D$ ). Functional stepping on the grid, which minimally recovered after the first stroke (Fig. $1 E$ ), dropped to a similar performance as initially observed after the first stroke (Fig. 7E, not significant).

For a subset of chronic animals that had undergone behavioral assessment before the retrograde tracing $(n=7)$, recovered performance (Fig. 1C-E; $28 \mathrm{~d}$ ) was compared with cell counts in the regions that had strengthened their projections into the strokeaffected hemicord (compare Fig. 4 and Fig. 5). In addition, behavioral scores were compared with cell counts in the stroke-affected cortical hemisphere (i.e., assessing the influence of spared cells). The variation in no single anatomical region did clearly account for the behavioral variation (comparison of normalized cell counts against behavioral performance; $n=7$; correlation coefficient cutoff at $R^{2}>0.81$ ). Hence, the behavioral outcome after stroke is evidently under the influence of factors that go beyond the mere number of cells in a given region projecting into the stroke-affected hemicord.

Overall, the functional recovery in the stroke-affected forelimb depends to a large part on the descending motor control of the contralesional motor cortex (i.e., ipsilateral to the impaired paw). Our anatomical findings suggest that the direct midlinecrossing corticospinal tract but also the ipsilateral descending corticoreticular and reticulospinal route may contribute to this ipsilateral control. Both pathways were shown to be strengthened in the present analysis.
B
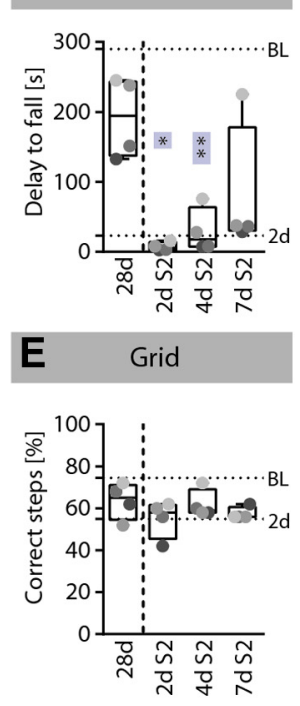

\section{Discussion}

Adult mice subjected to a one-sided photothrombotic stroke of the motor cortex showed functional deficits in the forepaw contralateral to the lesion, which recovered partially over the course of 2-4 weeks. We found that, in addition to the contralesional cortex, several brainstem nuclei increased their projections to the denervated cervical hemicord. Projections from the medullary reticular nuclei and the raphe nuclei to the denervated hemicord increased by up to $60 \%$ at 4 weeks after the stroke. Interestingly, these nuclei were also innervated more densely ( $60 \%$ ) by corticobulbar fibers from the contralesional cortex. Injury of the contralesional cortex 4 weeks after the first stroke abolished the recovered behaviors, suggesting important roles for the new, direct corticospinal as well as indirect corticoreticulospinal connections.

\section{Increase of ipsilateral corticospinal projections after stroke}

After cortical damage in newborn or juvenile rats, mice, or humans, the contralesional cortex is known to strengthen its connections to the denervated, ipsilateral spinal hemicord (Kartje-Tillotson et al., 1985; Benecke et al., 1991; Rouiller et al., 1991; Yoshikawa et al., 2011). In adult animals, sprouting of contralesional corticospinal fibers across the midline after large strokes or pyramidotomies occurs to a certain degree and could even be enhanced (e.g., by intense training, electrical stimulation, or counteracting growth inhibitory proteins) (Wiessner et al., 2003; Brus-Ramer et al., 2007; Maier et al., 2008). Here, in adult mice after a $90 \%$ destruction of the right primary and rostral motor cortex, 144 neurons of the left, contralesional cortex established new connections demonstrated by retrograde tracing to the denervated, left cervical segments C6-C7 (compared with 30 ipsilaterally projecting neurons in intact mice and 1206 cells in the right sensorimotor cortex). The new ipsilateral forelimb projecting cortical map strongly resembled that of the intact cortex with regard to the proportions between the rostral and caudal forelimb areas.

The mechanisms by which this neurite growth is induced are currently unknown. Motor cortical areas are interconnected with the corresponding, homotopic areas in the other hemisphere (Rouiller et al., 1994). After a stroke, this mostly inhibitory connection is lost (Shimizu et al., 2002). Yet, as seen in the partially spared rostral forelimb area, where the plasticity was prominent, the mere loss of the transcallosal connections is an unlikely cause for the side-switch of these neurons.

Sprouting of the ipsilesional secondary sensory cortex (S2) that was spared by the stroke is in agreement with previous reports of corticospinal sprouting of peri-infarct cortical areas (Nudo et al., 1996; Starkey et al., 2012). The function of these S2-spinal projections is currently unclear.

Importantly, the ablation of the initially spared motor cortex by a second stroke applied 4 weeks after the first induced the reappearance of the behavioral deficits that had previously recovered partially. Hence, the cortex contralateral to the initial stroke 
contributes to functional recovery, probably via direct corticospinal fibers to the denervated hemicord as well as via polysynaptic routes (e.g., through the brainstem reticular formation) (Benecke et al., 1991; Jankowska and Edgley, 2006).

\section{Differential changes of connections of specific brainstem nuclei to the stroke-affected cervical spinal cord}

In our mice, brainstem-spinal connections outnumbered the direct corticospinal fibers by a factor of $6-7$. Surprisingly, upon the change of input from the cortex and the loss of the cortical spinal innervations, the response of different (unlesioned) mesencephalic, pontine, and medullary brainstem-spinal systems to the stroke was found to be very heterogeneous. Some nuclei (e.g., the red nucleus or locus ceruleus) showed no change of their C6-C7 projections, many nuclei showed a slight decrease, and some regions, especially in the caudal medulla oblongata, showed increased connections resulting in up to a doubling of the retrogradely labeled neuron numbers. Most of these systems project ipsilaterally as well as contralaterally to the spinal cord, and plastic changes occurred on one or both sides. Many of the details of these pronounced anatomical changes in the phylogenetically oldest parts of the CNS remain to be elucidated and understood in their functional consequences.

\section{Brainstem-spinal plasticity is concentrated in the medullary reticular formation and the raphe nuclei}

Four weeks after stroke, a large number of reticulospinal neurons originating in Ncl. ret. gigantocellularis and the more caudal ventral medullary reticular nucleus have strengthened sparse preexisting or grown de novo projections into the stroke-affected cervical hemicord. Medullary reticular cells are closely linked to proximal and distal forelimb function in the nonhuman primate and in the rat (Isa et al., 2007; Riddle and Baker, 2010; Soteropoulos et al., 2012). The nucleus, which contains approximately twice as many neurons as the spinal-reconnected ipsilateral motor cortex, is therefore a good candidate for compensatory connections and functions after the stroke. This concept is supported by our anterograde tracing results of the corticobulbar connections from the contralesional sensorimotor cortex, which showed a $60 \%$ increase in terminal density in the medullary reticular and raphe nuclei.

The spinally projecting raphe nuclei (i.e., Ncl. raphe pallidus, magnus, and obscures) (Liang et al., 2011) consist of small cells located on and immediately around the sagittal midline of the medulla. They are one of the primary sources of serotonergic projections to the spinal cord (Bowker et al., 1981). Serotonin has neuromodulatory actions on sensory and motor spinal circuits (Schmidt and Jordan, 2000). These neurons are known to retain substantial ability to grow in the injured CNS (Cheng and Olson, 1995).

The strengthening of the corticoraphe and raphe-spinal pathway may, similar to the corticoreticulospinal pathway, reflect an anatomical route by which the ipsilateral neurons of the spared motor cortex gain control over the stroke-denervated spinal hemicord. The function of the slowly conducting serotonergic fibers may be to enhance neuronal excitability rendering spinal circuits receptive for other, more specific inputs.

\section{The challenge of the neurobiological mechanisms underlying tract plasticity}

The formation of corticospinal midline crossing fibers was seen after motor cortex stroke, pyramidotomy, and spinal cord injury. Here, very diverse responses of different brainstem-spinal systems to a unilateral cortical stroke and spinal cord denervation were seen, ranging from a doubling of the connections to no change or a decrease. The factors that determine whether, and how much, any given system sprouts remain entirely unclear at present. In the spinal cord, reactive microglia and astrocytes, or factors released by specific neurons in response to altered activity patterns, can be considered. More complex transneuronal trophic interactions may also occur.

In conclusion, we show that unilateral cortical strokes induce pronounced, but selective plastic changes in brainstem-spinal connections as well as in the corticobulbar innervation from the contralesional cortex. Particularly strong sprouting occurred in corticoreticular and reticulospinal projections, suggesting that the indirect corticoreticulospinal route may be a crucial pathway by which the remaining motor cortex can gain control over the ipsilateral, stroke-affected forelimb.

\section{References}

Bach LM, Magoun HW (1947) The vestibular nuclei as an excitatory mechanism for the cord. J Neurophysiol 10:331-337. Medline

Bácskai T, Fu Y, Sengul G, Rusznák Z, Paxinos G, Watson C (2013) Musculotopic organization of the motor neurons supplying forelimb and shoulder girdle muscles in the mouse. Brain Struct Funct 218:221-238. CrossRef Medline

Baker SN (2011) The primate reticulospinal tract, hand function and functional recovery. J Physiol 589:5603-5612. CrossRef Medline

Benecke R, Meyer BU, Freund HJ (1991) Reorganisation of descending motor pathways in patients after hemispherectomy and severe hemispheric lesions demonstrated by magnetic brain stimulation. Exp Brain Res 83: 419-426. Medline

Berridge KC (1989) Progressive degradation of serial grooming chains by descending decerebration. Behav Brain Res 33:241-253. CrossRef Medline

Bignall KE, Schramm L (1974) Behavior of chronically decerebrated kittens. Exp Neurol 42:519-531. CrossRef Medline

Bowker RM, Westlund KN, Coulter JD (1981) Origins of serotonergic projections to the spinal cord in rat: an immunocytochemical-retrograde transport study. Brain Res 226:187-199. CrossRef Medline

Brus-Ramer M, Carmel JB, Chakrabarty S, Martin JH (2007) Electrical stimulation of spared corticospinal axons augments connections with ipsilateral spinal motor circuits after injury. J Neurosci 27:13793-13801. CrossRef Medline

Bury SD, Jones TA (2002) Unilateral sensorimotor cortex lesions in adult rats facilitate motor skill learning with the "unaffected" forelimb and training-induced dendritic structural plasticity in the motor cortex. J Neurosci 22:8597-8606. Medline

Caramia MD, Iani C, Bernardi G (1996) Cerebral plasticity after stroke as revealed by ipsilateral responses to magnetic stimulation. Neuroreport 7:1756-1760. CrossRef Medline

Cheng H, Olson L (1995) A new surgical technique that allows proximodistal regeneration of 5-HT fibers after complete transection of the rat spinal cord. Exp Neurol 136:149-161. CrossRef Medline

Gamper E (1926) Bau und Leistungen eines menschlichen Mittelhirnwesens (Arhinencephalie mit Encephalocele) zugleich ein Beitrag zur Teratologie und Fasersystematik. Zeitschrift Neurologie Psychiatrie 102: 154-235. CrossRef

Ghosh A, Sydekum E, Haiss F, Peduzzi S, Zörner B, Schneider R, Baltes C, Rudin M, Weber B, Schwab ME (2009) Functional and anatomical reorganization of the sensory-motor cortex after incomplete spinal cord injury in adult rats. J Neurosci 29:12210-12219. CrossRef Medline

Hallett M (2001) Functional reorganization after lesions of the human brain: studies with transcranial magnetic stimulation. Rev Neurol (Paris) 157:822-826. CrossRef Medline

Heffner RS, Masterton RB (1983) The role of the corticospinal tract in the evolution of human digital dexterity. Brain Behav Evol 23:165-183. CrossRef Medline

Herzog A, Brösamle C (1997) 'Semifree-floating' treatment: a simple and fast method to process consecutive sections for immunohistochemistry and neuronal tracing. J Neurosci Methods 72:57-63. CrossRef Medline

Isa T, Ohki Y, Alstermark B, Pettersson LG, Sasaki S (2007) Direct and 
indirect cortico-motoneuronal pathways and control of hand/arm movements. Physiology 22:145-152. CrossRef Medline

Jankowska E, Edgley SA (2006) How can corticospinal tract neurons contribute to ipsilateral movements? A question with implications for recovery of motor functions. Neuroscientist 12:67-79. CrossRef Medline

Kartje-Tillotson G, Neafsey EJ, Castro AJ (1985) Electrophysiological analysis of motor cortical plasticity after cortical lesions in newborn rats. Brain Res 332:103-111. CrossRef Medline

Kennedy PR (1990) Corticospinal, rubrospinal and rubro-olivary projections: a unifying hypothesis. Trends Neurosci 13:474-479. CrossRef Medline

Lawrence DG, Kuypers HG (1968a) The functional organization of the motor system in the monkey: I. The effects of bilateral pyramidal lesions. Brain 91:1-14. CrossRef Medline

Lawrence DG, Kuypers HG (1968b) The functional organization of the motor system in the monkey: II. The effects of lesions of the descending brain-stem pathways. Brain 91:15-36. CrossRef Medline

Lee JK, Park MS, Kim YS, Moon KS, Joo SP, Kim TS, Kim JH, Kim SH (2007) Photochemically induced cerebral ischemia in a mouse model. Surg Neurol 67:620-625, discussion 625. CrossRef Medline

Liang H, Paxinos G, Watson C (2011) Projections from the brain to the spinal cord in the mouse. Brain Struct Funct 215:159-186. CrossRef Medline

Liang H, Paxinos G, Watson C (2012) Spinal projections from the presumptive midbrain locomotor region in the mouse. Brain Struct Funct 217: 211-219. CrossRef Medline

Liu Z, Chopp M, Ding X, Cui Y, Li Y (2013) Axonal remodeling of the corticospinal tract in the spinal cord contributes to voluntary motor recovery after stroke in adult mice. Stroke 44:1951-1956. CrossRef Medline

Maier IC, Baumann K, Thallmair M, Weinmann O, Scholl J, Schwab ME (2008) Constraint-induced movement therapy in the adult rat after unilateral corticospinal tract injury. J Neurosci 28:9386-9403. CrossRef Medline

McKenna JE, Prusky GT, Whishaw IQ (2000) Cervical motoneuron topography reflects the proximodistal organization of muscles and movements of the rat forelimb: a retrograde carbocyanine dye analysis. J Comp Neurol 419:286-296. CrossRef Medline

Nakagawa H, Ueno M, Itokazu T, Yamashita T (2013) Bilateral movement training promotes axonal remodeling of the corticospinal tract and recovery of motor function following traumatic brain injury in mice. Cell Death Dis 4:e534. CrossRef Medline

Nudo RJ, Wise BM, SiFuentes F, Milliken GW (1996) Neural substrates for the effects of rehabilitative training on motor recovery after ischemic infarct. Science 272:1791-1794. CrossRef Medline

Nygren LG, Fuxe K, Jonsson G, Olson L (1974) Functional regeneration of 5 -hydroxytryptamine nerve terminals in the rat spinal cord following 5,6-dihydroxytryptamine induced degeneration. Brain Res 78:377-394. CrossRef Medline

Omoto S, Ueno M, Mochio S, Yamashita T (2011) Corticospinal tract fibers cross the ephrin-B3-negative part of the midline of the spinal cord after brain injury. Neurosci Res 69:187-195. CrossRef Medline

Raineteau O, Schwab ME (2001) Plasticity of motor systems after incomplete spinal cord injury. Nat Rev Neurosci 2:263-273. CrossRef Medline

Riddle CN, Baker SN (2010) Convergence of pyramidal and medial brain stem descending pathways onto macaque cervical spinal interneurons. J Neurophysiol 103:2821-2832. CrossRef Medline

Rosenzweig ES, Courtine G, Jindrich DL, Brock JH, Ferguson AR, Strand SC, Nout YS, Roy RR, Miller DM, Beattie MS, Havton LA, Bresnahan JC, Edgerton VR, Tuszynski MH (2010) Extensive spontaneous plasticity of corticospinal projections after primate spinal cord injury. Nat Neurosci 13:1505-1510. CrossRef Medline

Rossini PM, Calautti C, Pauri F, Baron JC (2003) Post-stroke plastic reorganisation in the adult brain. Lancet Neurol 2:493-502. CrossRef Medline
Rouiller EM, Liang FY, Moret V, Wiesendanger M (1991) Trajectory of redirected corticospinal axons after unilateral lesion of the sensorimotor cortex in neonatal rat: a phaseolus vulgaris-leucoagglutinin (PHA-L) tracing study. Exp Neurol 114:53-65. CrossRef Medline

Rouiller EM, Babalian A, Kazennikov O, Moret V, Yu XH, Wiesendanger M (1994) Transcallosal connections of the distal forelimb representations of the primary and supplementary motor cortical areas in macaque monkeys. Exp Brain Res 102:227-243. CrossRef Medline

Schmidt BJ, Jordan LM (2000) The role of serotonin in reflex modulation and locomotor rhythm production in the mammalian spinal cord. Brain Res Bull 53:689-710. CrossRef Medline

Shanina EV, Schallert T, Witte OW, Redecker C (2006) Behavioral recovery from unilateral photothrombotic infarcts of the forelimb sensorimotor cortex in rats: role of the contralateral cortex. Neuroscience 139:14951506. CrossRef Medline

Shimizu T, Hosaki A, Hino T, Sato M, Komori T, Hirai S, Rossini PM (2002) Motor cortical disinhibition in the unaffected hemisphere after unilateral cortical stroke. Brain 125:1896-1907. CrossRef Medline

Soteropoulos DS, Williams ER, Baker SN (2012) Cells in the monkey pontomedullary reticular formation modulate their activity with slow finger movements. J Physiol 590:4011-4027. CrossRef Medline

Starkey ML, Bleul C, Zörner B, Lindau NT, Mueggler T, Rudin M, Schwab ME (2012) Back seat driving: hindlimb corticospinal neurons assume forelimb control following ischaemic stroke. Brain 135:3265-3281. CrossRef Medline

Taub E, Crago JE, Burgio LD, Groomes TE, Cook EW 3rd, DeLuca SC, Miller NE (1994) An operant approach to rehabilitation medicine: overcoming learned nonuse by shaping. J Exp Anal Behav 61:281-293. CrossRef Medline

Tennant KA, Adkins DL, Donlan NA, Asay AL, Thomas N, Kleim JA, Jones TA (2011) The organization of the forelimb representation of the C57BL/6 mouse motor cortex as defined by intracortical microstimulation and cytoarchitecture. Cereb Cortex 21:865-876. CrossRef Medline

Travis AM, Woolsey CN (1956) Motor performance of monkeys after bilateral partial and total cerebral decortications. Am J Phys Med 35:273-310. Medline

Ueno M, Hayano Y, Nakagawa H, Yamashita T (2012) Intraspinal rewiring of the corticospinal tract requires target-derived brain-derived neurotrophic factor and compensates lost function after brain injury. Brain 135:1253-1267. CrossRef Medline

Valverde F (1962) Reticular formation of the albino rat's brain stem cytoarchitecture and corticofugal connections. J Comp Neurol 119:25-53. CrossRef Medline

Welmer AK, Widén Holmqvist L, Sommerfeld DK (2010) Location and severity of spasticity in the first $1-2$ weeks and at 3 and 18 months after stroke. Eur J Neurol 17:720-725. CrossRef Medline

Whishaw IQ (2004) The behavior of the laboratory rat. In: A handbook with tests. Oxford: Oxford UP.

Wiessner C, Bareyre FM, Allegrini PR, Mir AK, Frentzel S, Zurini M, Schnell L, Oertle T, Schwab ME (2003) Anti-Nogo-A antibody infusion $24 \mathrm{~h}$ after experimental stroke improved behavioral outcome and corticospinal plasticity in normotensive and spontaneously hypertensive rats. J Cereb Blood Flow Metab 23:154-165. Medline

Woods JW (1964) Behavior of chronic decerebrate rats. J Neurophysiol 27: 635-644. Medline

Yoshikawa A, Atobe Y, Takeda A, Kamiya Y, Takiguchi M, Funakoshi K (2011) A retrograde tracing study of compensatory corticospinal projections in rats with neonatal hemidecortication. Dev Neurosci 33:539-547. CrossRef Medline

Zhao S, Zhao M, Xiao T, Jolkkonen J, Zhao C (2013) Constraint-induced movement therapy overcomes the intrinsic axonal growth-inhibitory signals in stroke rats. Stroke 44:1698-1705. CrossRef Medline 